\title{
Quantum Chemical Investigations on the Hydrolysis of Gold(III)- Based Anticancer Drugs and Their Interaction with Amino Acid Residues
}

\author{
Amit Kumar Pradhan, Abhijit Shyam, and Paritosh Mondal*
}

Cite This: ACS Omega 2021, 6, 28084-28097

Read Online

ABSTRACT: A comprehensive hydrolysis mechanism of the promising class of $\mathrm{Au}(\mathrm{III})$ anticancer drugs $\left[\mathrm{Au}(\mathrm{DMDT}) \mathrm{Cl}_{2}\right](\mathrm{DMDT}=\mathrm{N}, \mathrm{N}$-dimethyldithiocarbamate $)(\mathbf{R})$ and $\left[\mathrm{Au}(\right.$ damp $\left.) \mathrm{Cl}_{2}\right]($ damp $=2-[$ (dimethylamino) methyl $]$ phenyl) $\left(\mathbf{R}^{\prime}\right)$ was done by means of density functional theory (DFT) in combination with the CPCM solvation model to explore the solution behavior and stability under physiological conditions. The activation free energies $(\Delta G)$ for the second hydrolysis, $\mathbf{R}(13.7 \mathrm{kcal} / \mathrm{mol})$ and $\mathbf{R}^{\prime}(10.0 \mathrm{kcal} / \mathrm{mol})$ are found to be relatively lower in comparison to the first hydrolysis, and their rate constant values are computed to be $5.62 \times 10^{2}$ and $2.90 \times 10^{5} \mathrm{~s}^{-1}$, respectively. Besides these, the interaction mechanisms of aquated $\mathbf{R}$ and $\mathbf{R}^{\prime}$ with the potential protein-binding sites cysteine (Cys) and selenocysteine ( $\mathrm{Sec}$ ) were also investigated in detail. The kinetic study and activation Gibbs free energy profiles reveal that the aquated complexes of $\mathbf{R}$ and $\mathbf{R}^{\prime}$ bind more effectively to the Se site of Sec than to the $S$

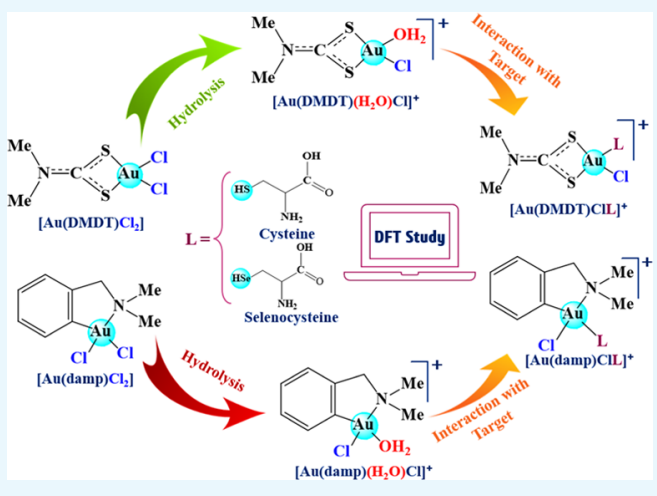
site of Cys. Intra- and intermolecular hydrogen bonding play a pivotal role in stabilizing the intermediates and transition states involved in the ligand substitution reactions of $\mathbf{R}$ and $\mathbf{R}^{\prime}$. Natural population analysis (NPA) was done to determine the charge distributions on important atoms during the hydrolysis and ligand substitution reactions.

\section{INTRODUCTION}

The development of numerous effective chemotherapeutic drugs has made a significant breakthrough in the treatment of cancer. In the past few decades, metal complexes have gained considerable attention in the field of potential chemotherapeutic drug designing. However, the journey of metal-based anticancer research initiated with the discovery of the antineoplastic activity of cisplatin by Barnett Rosenberg in the 1960s. ${ }^{1}$ Since the development and approval of cisplatin by the Food and Drug Administration (FDA) for use in humans as a promising anticancer drug, a series of platinum-based complexes have been screened for antitumor activity. Cisplatin and other platinumbased anticancer drugs play a crucial role in the treatment of a broad spectrum of cancers. Nonetheless, the worsening side effects of platinum-based drugs encouraged researchers to discover novel anticancer drugs with minimal side effects and higher cytotoxicity. ${ }^{2-6}$ It is well documented that the in vivo and in vitro activities of anticancer drugs are regulated by the choice of the metal center. Hence, considerable efforts have been devoted towards the rational designing of $\mathrm{Ru}-$, Os-, and $\mathrm{Au}-$ based therapeutic agents to overcome the limitations of platinum-based drugs. ${ }^{7-11}$ Undeniably, among the synthesized nonplatinum anticancer drugs, $\mathrm{Au}$ (III) complexes have attracted much attention because of their strong enzyme-inhibitory effects on tumor cell growth and proliferation. ${ }^{12-15}$ Both $\mathrm{Au}(\mathrm{III})$ and $\mathrm{Pt}(\mathrm{II})$ complexes possess the same $\mathrm{d} 8$ electronic configuration and form an identical square planar geometry. However, Au(III) complexes show relatively faster ligand substitution kinetics in comparison to platinum-based anticancer drugs. ${ }^{6,16,17}$ Numerous $\mathrm{Au}$ (III) complexes are known to exhibit superior in vitro cytotoxicity toward a series of human cancer cell lines. ${ }^{18,19}$ On the contrary, recent studies have revealed that unlike cisplatin and its derivatives, $\mathrm{Au}$ (III) complexes do not show strong interaction with calf thymus DNA; rather, they exhibit a high propensity for targeting enzymes as well as mitochondria. ${ }^{20-22}$ These properties led to the classification of $\mathrm{Au}$ (III) complexes as versatile metallodrugs with an effective and altered mode of anticancer activity.

Furthermore, highly redox active $\mathrm{Au}$ (III) complexes are easily reduced to $\mathrm{Au}(\mathrm{I})$ or even $\mathrm{Au}(0)$ by intracellular reducing substances (such as methionine, glycine, and albumin) under physiological conditions, which has restricted their clinical uses. ${ }^{23}$ However, the reduction of $\mathrm{Au}$ (III) complexes can be prevented and stabilities can be improved by choosing specific multidentate chelating ligands with nitrogen or sulfur as donor

Received: August 4, 2021

Accepted: October 6, 2021

Published: October 15, 2021 
Scheme 1. Proposed Pathways for the Hydrolysis of $\left[\mathrm{Au}(\mathrm{DMDT}) \mathrm{Cl}_{2}\right](\mathrm{R})$ and $\left[\mathrm{Au}(\mathrm{damp}) \mathrm{Cl}_{2}\right]\left(\mathrm{R}^{\prime}\right)$

\section{Hydrolysis Steps of $\left[\mathrm{Au}(\mathrm{DMDT}) \mathrm{Cl}_{2}\right]$}

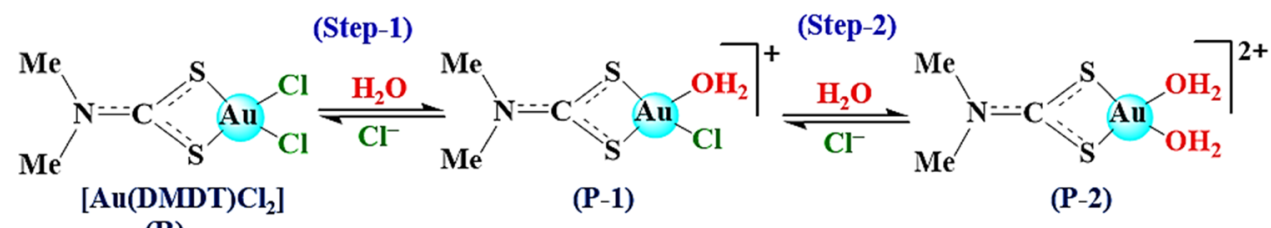

(R)

Hydrolysis Steps of $\left[\mathrm{Au}(\operatorname{damp}) \mathrm{Cl}_{2}\right]$

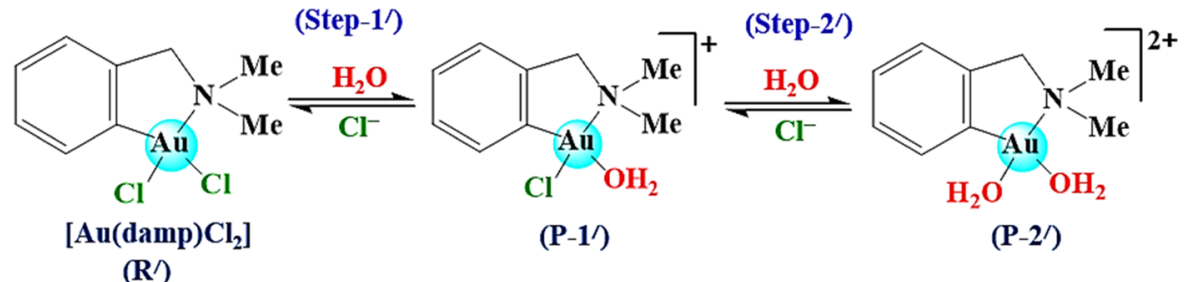

atoms. $^{24,25}$ The dithiocarbamate moiety as a bidentate ligand has received much attention in recent years because it may easily undergo substitution reactions in cation-bound ligands. Ronconi et al. reported some stable $\mathrm{Au}(\mathrm{III})$ dithiocarbamate derivatives, namely $\left[\mathrm{Au}(\mathrm{DMDT}) \mathrm{X}_{2}\right][\mathrm{DMDT}=(N, N$-dimethyldithiocarbamate); $\left.\mathrm{X}=\mathrm{Cl}^{-}, \mathrm{Br}^{-}\right]$, having a superior chemotherapeutic index with higher solubility in aqueous medium and greater cytotoxicity. ${ }^{26}$ Among the plethora of $\mathrm{Au}(\mathrm{III})-\mathrm{DMDT}$ complexes, $\left[\mathrm{Au}(\mathrm{DMDT}) \mathrm{Cl}_{2}\right]$ (R) exhibits 14-fold cytotoxicity than cisplatin against a panel of human tumor cells and is able to overcome the cisplatin resistance. ${ }^{27,28}$ Cattaruzza et al. reported the outstanding antitumor activity of $\mathbf{R}$ against the proliferation of androgen-resistant prostate cancer cells in a xenograft model. ${ }^{29}$ A promising class of stable organogold(III) complexes $\left[\mathrm{Au}(\right.$ damp $\left.) \mathrm{X}_{2}\right](($ damp $=2$ [(dimethylamino)methyl $]$ phenyl $) ; \mathrm{X}=\mathrm{Cl}^{-}, \mathrm{CN}^{-}$, acetate $)$ were designed by Parish and his co-workers, which are selectively active against the human bladder tumor cell line (HT1376) and ovarian tumor cell lines. ${ }^{30,31}$ Among them, $\left[\mathrm{Au}(\right.$ damp $\left.) \mathrm{Cl}_{2}\right]\left(\mathbf{R}^{\prime}\right)$ was found to exhibit comparable or greater cytotoxic effects than cisplatin against several human cancer cell lines, including colon, breast, rectum, bladder, and ovary cancers. $^{31}$

Generally, metal-based drugs often act as pro-drugs that undergo ligand substitution or redox reactions before interacting with the targets. ${ }^{32-34}$ Thus, it is essential to understand the specific activation strategy of each class of drugs to tune their activity. Although the precise mechanism of action of $\mathrm{Au}$ (III) complexes is still under investigation, the solution chemistry of $\mathrm{Au}(\mathrm{III})$-based anticancer drugs is much significant in order to study their stability under physiological conditions, as the $\mathrm{Au}(\mathrm{III})$ complexes are readily hydrolyzed to their corresponding aquated complexes. Several research groups have investigated the solvent effect on $\mathrm{Au}$ (III) complexes and reported that the halogen atoms of the complexes can readily be hydrolyzed to the more water-soluble hydroxo derivatives. ${ }^{35-39}$ Ronconi et al. also explored the possibility of the water solubility of $\mathrm{Au}(\mathrm{III})-$ DMDT complexes and found that the complex is stable in DMSO but undergoes quick hydrolysis in physiological environment to yield cationic $\mathrm{Au}$ (III)-damp species. ${ }^{26}$ Surprisingly, the DMDT derivative of $\mathbf{R}$ has been shown to undergo complete hydrolysis under physiological condition. The oxidation state of gold remains at +3 even after hydrolysis due to the stabilization effects of the chelating dithiocarbamate ligand. Buckley et al. reported that the anticancer $\mathrm{Au}(\mathrm{III})$ complex $\mathbf{R}^{\prime}$ is stable in DMSO and undergoes rapid hydrolysis in physiological condition. ${ }^{30}$

Most of the thiol-containing enzymes, such as thioredoxin reductases (TrxR), glutathione reductase (GR), and cysteine protease, are seen to be overexpressed in various cancer cell lines and tissues. Enzymes GR and TrxR contain cysteinyl thiols or selenocysteine in their active sites. They play a vital role in the redox regulation of important cellular processes such as DNA synthesis, transcription, cell growth, and drug resistance. ${ }^{40,41}$ These thiol-containing enzymes are potential targets for anticancer $\mathrm{Au}(\mathrm{III})$ complexes. $^{42-44} \mathrm{Au}(\mathrm{III})$ complexes can inhibit TrxR activity by progressive oxidative damage of cysteine and selenocysteine residues. ${ }^{45,46}$ Liao et al. investigated the interaction of cysteine with hydrolyzed $\left[\mathrm{Au}(\mathrm{DMDT}) \mathrm{Cl}_{2}\right]$ and showed that the soft $\mathrm{Au}$ (III) prefers the $\mathrm{S}$ site of cysteine over the $\mathrm{N}$ site. ${ }^{47}$ Tolbatov et al. carried out theoretical investigation on the interaction of gold $\mathrm{Au}(\mathrm{I}) \mathrm{N}$-heterocyclic carbine complexes with the potential protein-binding sites. Their findings specify that cysteine and selenocysteine are the preferential targets for gold-based anticancer drugs. ${ }^{48,49}$

Although few experimental reports on the hydrolysis of $\mathbf{R}$ and $\mathbf{R}^{\prime}$ are available, a theoretical investigation at the molecular level still needs to be performed. Therefore, we have reported for the first time a detailed plausible hydrolysis mechanism of $\mathbf{R}$ and $\mathbf{R}^{\prime}$ in the present work using density functional theory (DFT) in combination with the CPCM solvation model. In addition, the interaction of cysteine (Cys) and selenocysteine (Sec) with hydrolyzed $\mathbf{R}$ and $\mathbf{R}^{\prime}$ has also been presented.

\section{RESULTS AND DISCUSSION}

Herein, the structural properties and activation free energies for the hydrolysis of $\mathbf{R}$ and $\mathbf{R}^{\prime}$ as well as the substitution of aqua ligands from hydrolyzed $\mathbf{R}$ and $\mathbf{R}^{\prime}$ by $\mathbf{C y s}$ and Sec molecules have been explored in detail. For the sake of simplicity, the stationary points such as reactant intermediates (RCs), transition states (TSs), and product intermediates (PCs) involved in ligand substitution reactions of $\mathbf{R}$ are labeled as RC-N, TS-N, and PC-N, respectively. Meanwhile, RC-N', TS$\mathbf{N}^{\prime}$, and PC-N' are used for the RCs, TSs, and PCs, respectively, involved in the ligand exchange reactions of $\mathbf{R}^{\prime}$. Here, "N" represents the different steps of the reaction. Details analysis of 


\section{Step-1: First $\mathrm{Cl}$ ligand hydrolysis of $\mathbf{R}$}

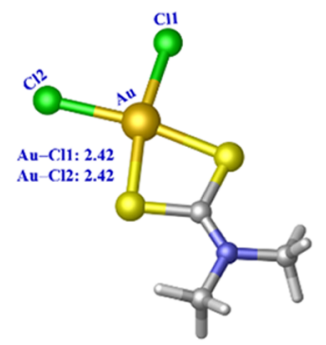

$\mathbf{R}$

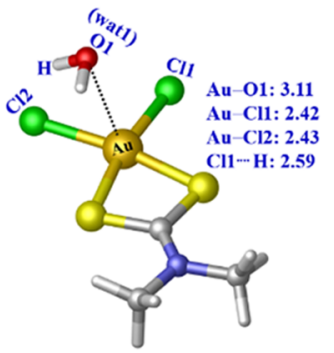

RC-1

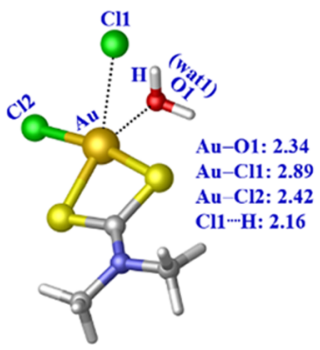

TS-1

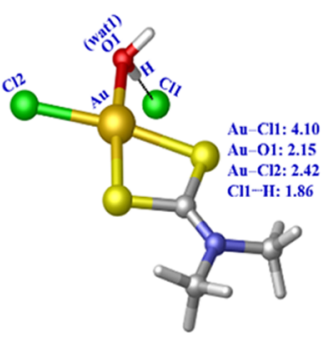

PC-1

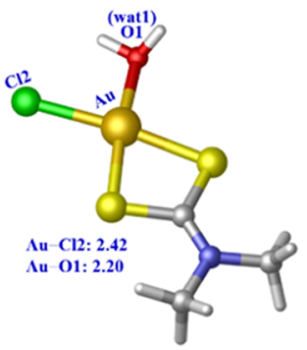

P-1

Step-2: Second Cl ligand hydrolysis of $\mathbf{R}$

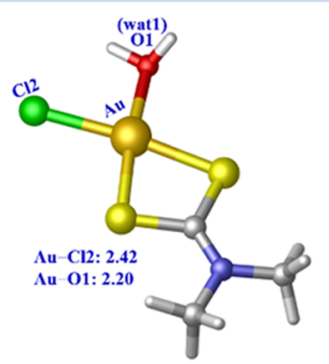

P-1

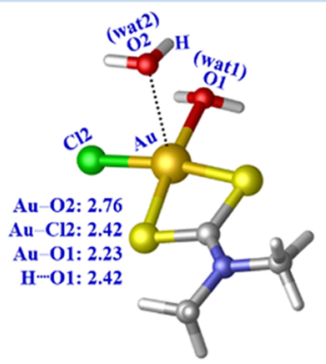

RC-2

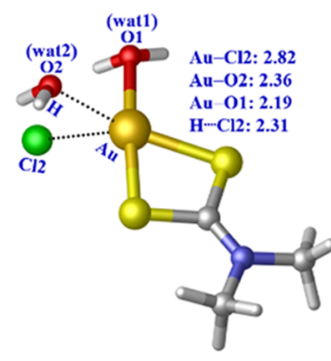

TS-2

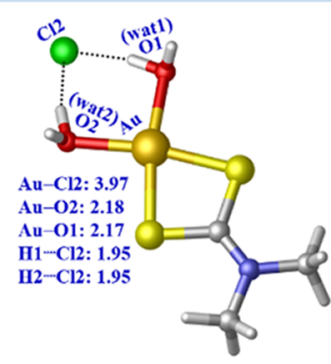

PC-2

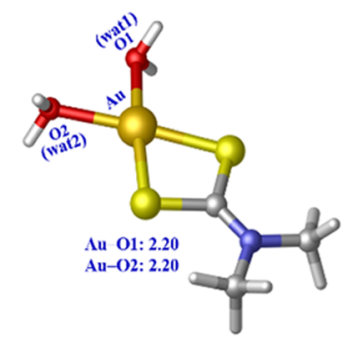

P-2

Figure 1. Optimized structures of all of the stationary points involved in the hydrolysis of $\mathbf{R}$, calculated at B3LYP/(LanL2DZ/6-31G(d,p)) in aqueous medium. All bond distances are expressed in units of $\AA$.

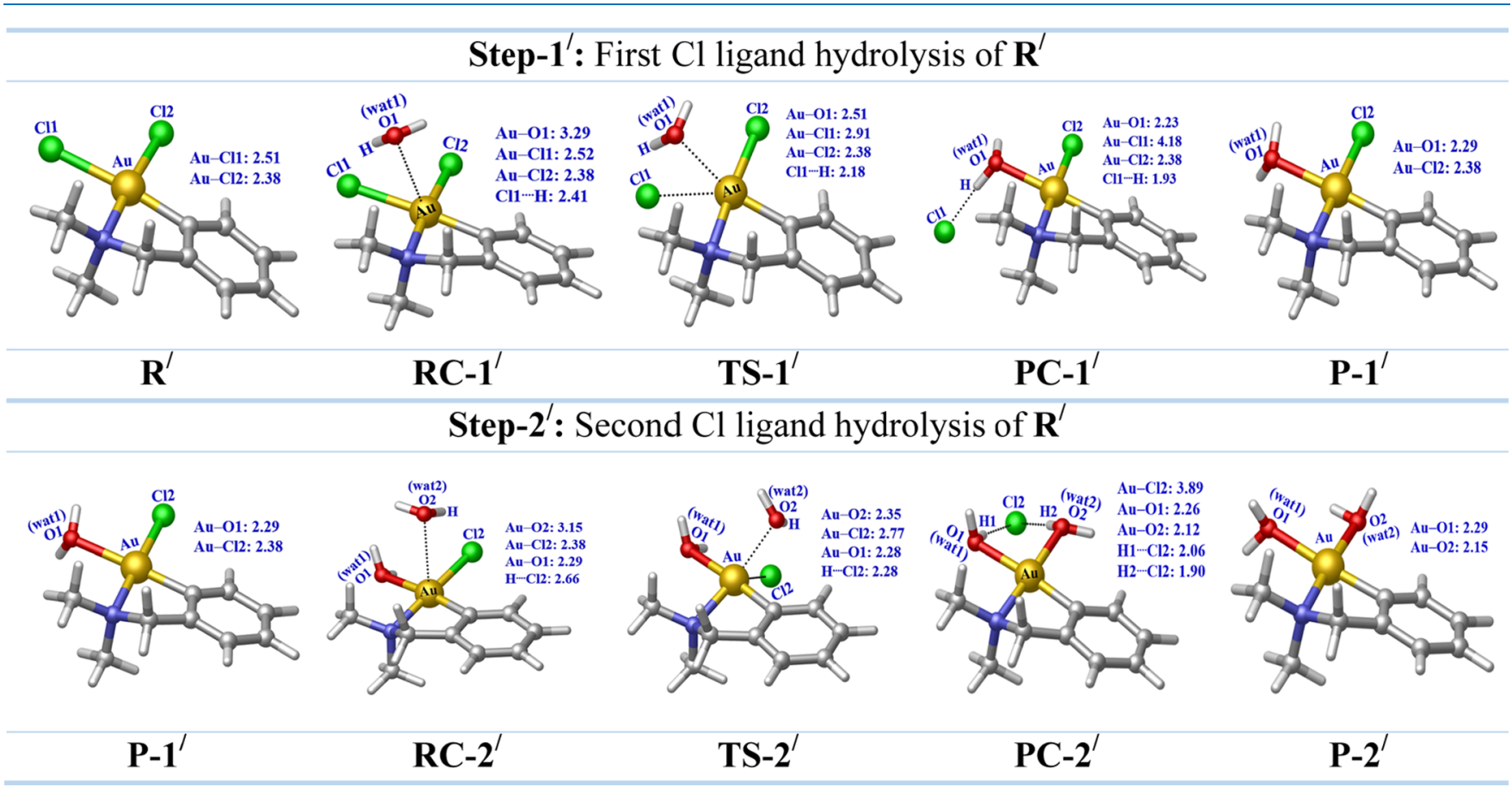

Figure 2. Optimized structures of all of the stationary points involved in the hydrolysis of $\mathbf{R}^{\prime}$, calculated at B3LYP/(LanL2DZ/6-31G(d,p)) in aqueous medium. All the bond distances are expressed in units of $\AA$.

the optimized geometries and energetics are discussed in the subsequent sections.

2.1. Structural Characteristics. DFT-optimized geometries reveal that the reactants and products adopt a square planar geometry, whereas the transition states are found to attain pentacoordinated trigonal bipyramid (TBP) structures. More- over, mechanistic investigations have confirmed that the hydrolysis of $\mathrm{Au}(\mathrm{III})$ complexes and substitution of aqua ligands from hydrolyzed square planar $\mathrm{Au}$ (III) complexes follow a dissociative interchange mechanism $\left(\mathbf{I}_{\mathbf{d}}\right)$, through the pentacoordinated transition states. 
Scheme 2. Proposed Pathways for the Interaction of Aquated R Complexes with the S Site of Cys and Se Site of Sec

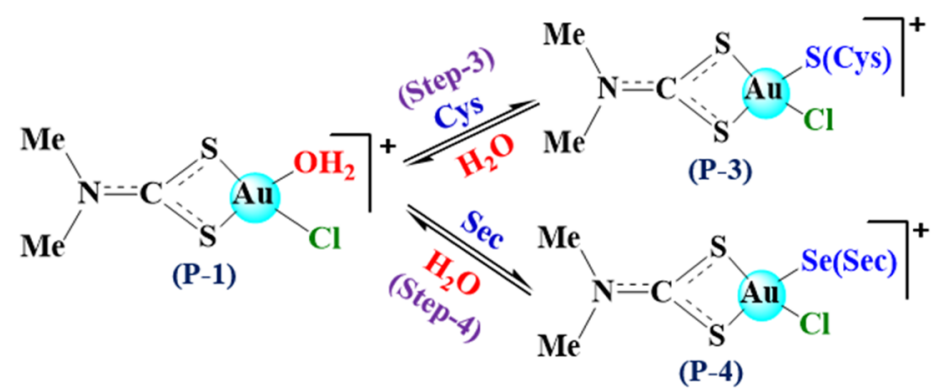

(P-4)

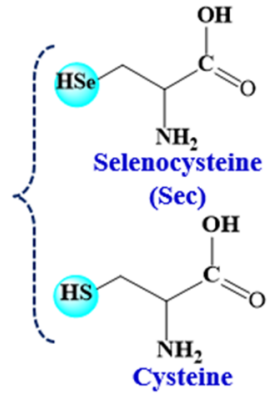

(Cys)

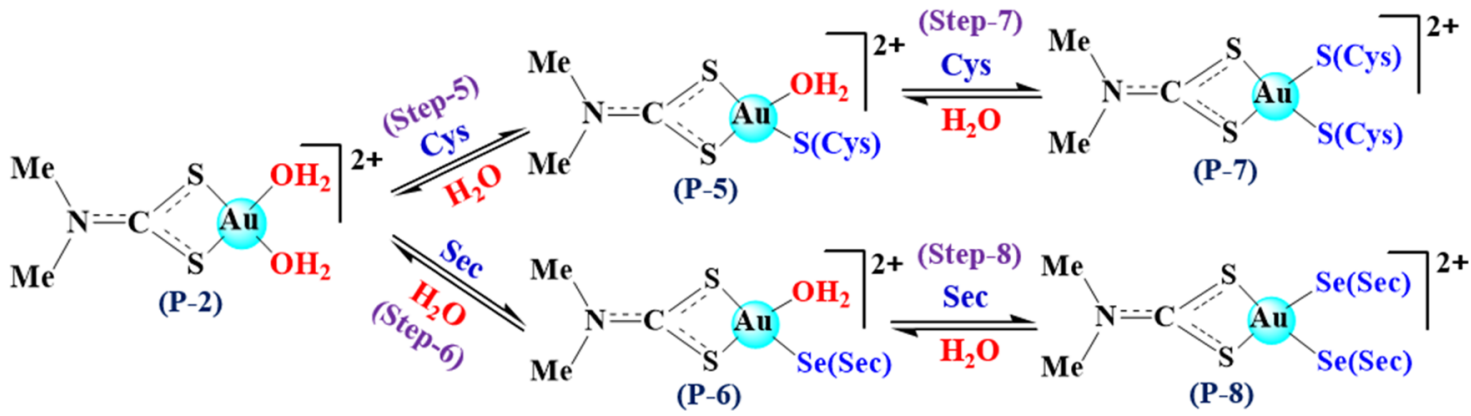

2.1.1. Hydrolysis of $R$ and $R^{\prime}$. In this section, the important geometrical parameters of all of the stationary points involved in the two-step hydrolysis of $\mathbf{R}$ and $\mathbf{R}^{\prime}$ are described; the proposed reaction pathways are schematically represented in Scheme 1. The optimized stationary points of the first and second hydrolysis steps of $\mathbf{R}$ and $\mathbf{R}^{\prime}$ are shown in Figures 1 and 2, respectively, and significant geometrical parameters are summarized in Table S1. In addition, the hydrolysis of $\mathbf{R}^{\prime}$ has been investigated with two probable pathways due to the asymmetric nature of the 2-[(dimethylamino)methyl $]$ phenyl group present in $\mathbf{R}^{\prime}$. The most favorable pathways representing the hydrolysis of $\mathbf{R}^{\prime}$ are shown in Scheme 1, while the comparatively less favorable pathways are incorporated in SI. In the first hydrolysis, one of the two chlorido ligands from $\mathbf{R}$ and $\mathbf{R}^{\prime}$ is replaced by the aqua ligand, which leads to the formation of monoaquated products (P-1 and $\left.\mathbf{P}-\mathbf{1}^{\prime}\right)$. These monoaquated products then undergo the second hydrolysis to form diaquated complexes (P-2 and $\left.\mathbf{P}-\mathbf{2}^{\prime}\right)$. Step-1 and Step-1' in Scheme 1 indicate the first hydrolysis of $\mathbf{R}$ and $\mathbf{R}^{\prime}$, respectively, whereas the second hydrolysis is represented by Step-2 (for $\mathbf{R}$ ) and Step-2' (for $\mathbf{R}^{\prime}$ ). The presence of hydrogen bonding ( $\mathbf{H}$-bonds) leads to the stabilization of the stationary points RCs, TSs, and PCs, and hence, the activation free energy for the hydrolysis process is lowered. All of the $\mathrm{H}$-bonding distances are evaluated to be in the range of 1.86-2.66 $\AA$. Figures 1 and 2 show the interaction of $\mathbf{R}$ and $\mathbf{R}^{\prime}$, respectively with the incoming aqua ligand through the H-bonding in RCs to yield the corresponding hydrolyzed products. Replacement of the first chlorido ligand with aqua ligand from $\mathbf{R}$ and $\mathbf{R}^{\prime}$ results in the monoaquated products $\mathbf{P}-\mathbf{1}$ and $\mathbf{P}-\mathbf{1}^{\prime}$ via transition states TS-1 and TS-1' $\mathbf{1}^{\prime}$, respectively. The incoming aqua ligand interacts with adjacent chlorido ligands through hydrogen bonding at distances of $2.59 \AA$ (RC-1) and $2.41 \AA\left(\mathbf{R C}^{\prime} \mathbf{1}^{\prime}\right)$, while the $\mathrm{Au}-\mathrm{Cl} 1$ bond distance in RC-1 is $2.42 \AA$ and that in R-1' ${ }^{\prime}$ is noticed to be $2.52 \AA$. In TS-1 and TS$\mathbf{1}^{\prime}$, the most important structural changes that have been observed are the decrease of the $\mathrm{Au}-\mathrm{O} 1$ (wat1) distances from 3.11 to 2.34 and 3.29 to $2.51 \AA$, respectively, and the simultaneous elongation of $\mathrm{Au}-\mathrm{Cl1}$ bond distances by 0.47 and $0.39 \AA$. The hydrogen bonding in TSs facilitates the substitution of the leaving chlorido ligand and the formation of the $\mathrm{Au}-\mathrm{O} 1$ (wat1) bond. In the process of hydrolysis, the chlorido ligand leaves the $\mathrm{Au}(\mathrm{III})$ center and remains attached with the aqua ligand through $\mathrm{H}$-bonding in the case of PC-1 and PC-1'. Finally, monoaquated $\mathbf{P - 1}$ and $\mathbf{P}-\mathbf{1}^{\prime}$ are formed with the complete release of the chlorido ligand, and the $\mathrm{Au}-\mathrm{O} 1$ (wat1) distances are calculated to be 2.20 and $2.29 \AA$, respectively.

Yet again, monoaquated species $\mathbf{P}-\mathbf{1}$ and $\mathbf{P}-\mathbf{1}^{\prime}$ formed from the first hydrolysis are considered as reactants for the second hydrolysis step. Hydrolysis of the existing chlorido ligand of P-1 and $\mathbf{P}-\mathbf{1}^{\prime}$ gives diaquated products $\mathbf{P}-\mathbf{2}$ and $\mathbf{P}-\mathbf{2}^{\prime}$ via transition states TS-2 and TS-2'. The incoming aqua ligand forms $\mathrm{H}$ bonding with the already bonded aqua ligand at a distance of $\mathbf{H}($ wat 2$) \cdots \mathbf{O l}$ (wat 1$)=2.42 \AA$ (Figure 1$)$ in RC-2, while the incoming aqua ligand in RC-2' forms H-bonding with the chlorido ligand at a $\mathbf{H}$ (wat2) $\cdots \mathbf{C l} 2$ distance of $2.66 \AA$ (Figure 2). The $\mathrm{Au}-\mathrm{O} 2$ (wat2) distance is shortened and $\mathrm{Au}-\mathrm{Cl} 2$ bond length is elongated in TS-2 and TS-2', while in PCs, the leaving chlorido ligand remains attached to the two aqua ligands via two hydrogen bondings. Lastly, the newly formed $\mathrm{Au}-\mathrm{O} 2$ (wat2) bond distances in P-2 and P-2' are evaluated to be 2.20 and 2.15 Å, respectively.

2.1.2. Interaction of Aquated $R$ Complexes with Cys and $\mathrm{Sec}$. Herein, a systematic investigation on the interactions of the monoaquated (P-1) and diaquated (P-2) complexes of $\mathbf{R}$ with the $S$ site of cysteine (Cys) and Se site of selenocysteine (Sec) has been carried out using the DFT method. The replacement of the aqua ligand in P-1 with Cys and Sec leads to the formation of P-3 (Step-3) and P-4 (Step-4). Substitution of the first aqua ligand from P-2 with Cys leads to P-5 (Step-5) and with Sec results in P-6 (Step-6). Complexes P-5 and P-6 then further undergo the second aqua ligand substitution reaction with $\mathbf{C y s}$ and Sec, respectively, and result in double Cys/Sec-substituted products P-7 (Step-7) and P-8 (Step-8). The diagrammatic representations of the aqua ligand substitution of $\mathbf{P}-\mathbf{1}$ and $\mathbf{P - 2}$ are shown in Scheme 2. The structural parameters of all of the stationary points involved in these processes are listed in Table 

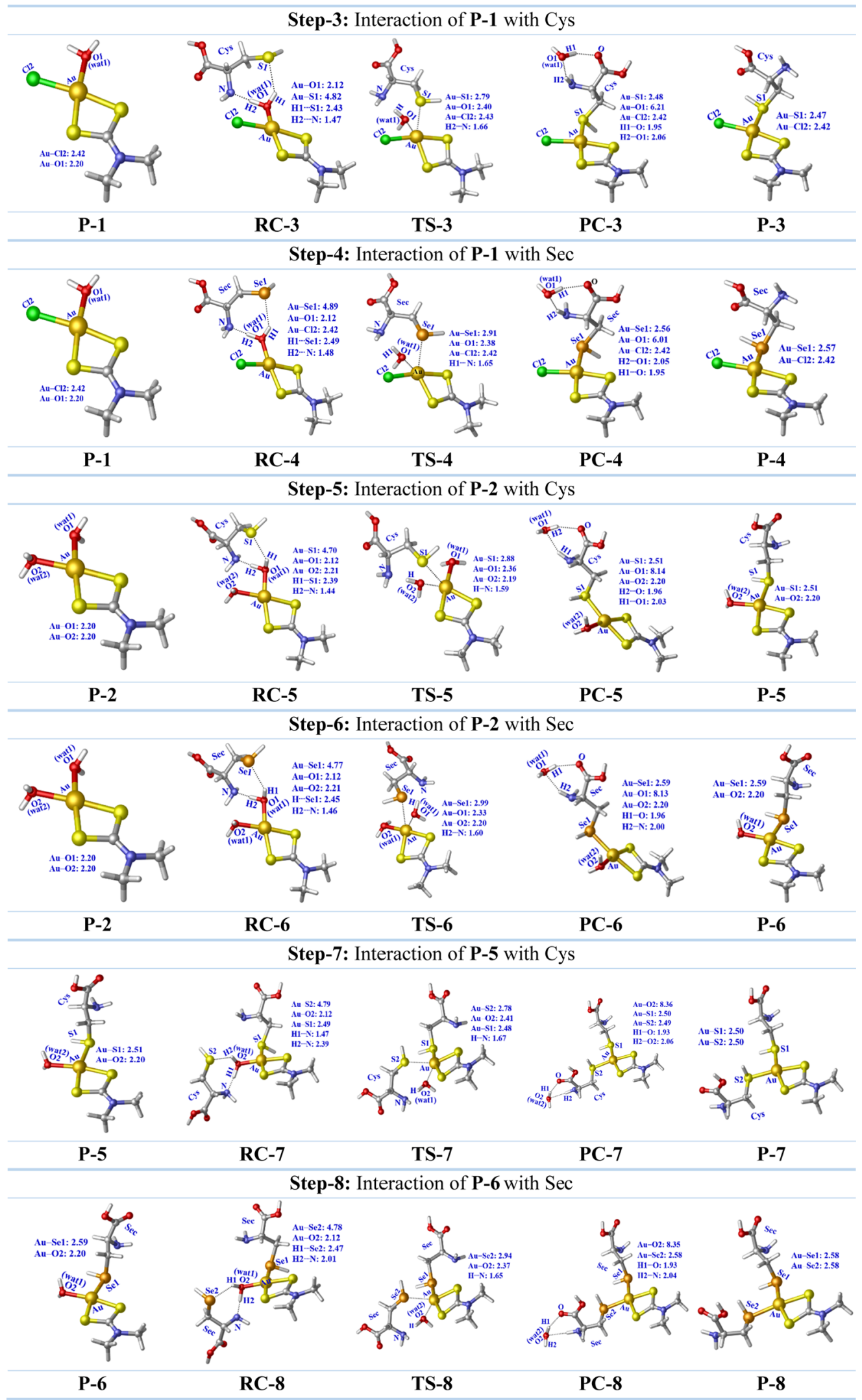

Figure 3. Optimized structures of all of the stationary points involved in the interaction of aquated $\mathbf{R}$ complexes with Cys and Sec, calculated at $\mathrm{B} 3 \mathrm{LYP} /(\mathrm{LanL} 2 \mathrm{DZ} / 6-31 \mathrm{G}(\mathrm{d}, \mathrm{p}))$ in aqueous medium. Bond distances are expressed in units of $\AA$.

S2, while the optimized geometries are displayed in Figure 3. During these substitution reactions, the incoming biomolecules (Cys or Sec) form H-bonding with coordinated aqua ligands. H- bondings are mainly responsible for initiating the substitution reaction and also stabilizing the corresponding intermediates. Again, the $\mathrm{Au}-\mathrm{O}\left(\mathrm{H}_{2} \mathrm{O}\right)$ bond is gradually weakened under the 
Scheme 3. Proposed Pathways for the Interaction of Aquated $\mathrm{R}^{\prime}$ Complexes with the S Site of Cys and Se Site of Sec

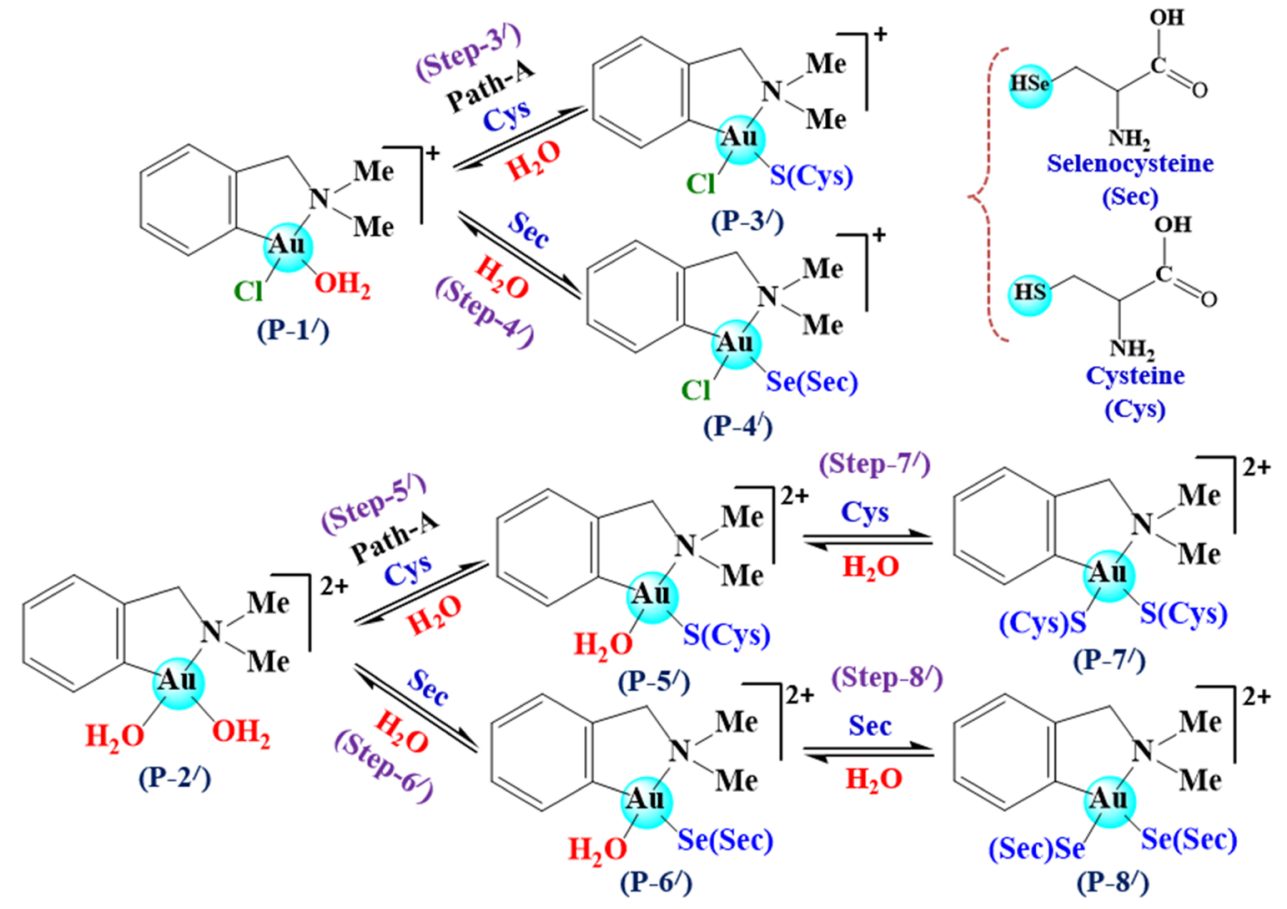

influence of the incoming Cys or Sec and results in the cleavage of the $\mathrm{Au}-\mathrm{O}\left(\mathrm{H}_{2} \mathrm{O}\right)$ bond and simultaneous formation of $\mathrm{Au}-$ $\mathrm{S}(\mathrm{Cys})$ or $\mathrm{Au}-\mathrm{Se}(\mathrm{Sec})$ bonds. All of the transition states involved in these substitution reactions are confirmed by the presence of only one negative frequency. Nevertheless, the resultant imaginary frequencies are of a low magnitude, in the range of -65.12 to $-73.23 \mathrm{~cm}^{-1}$, which signifies a flat potential energy surface (PES) along the reaction coordinate in TSs. It is observed that the distance between $\mathrm{Au}$ and the leaving $\mathrm{O}\left(\mathrm{H}_{2} \mathrm{O}\right)$ atom is increased from 2.12 to $8.36 \AA$; subsequently, the bond length between $\mathrm{Au}$ and the incoming $\mathrm{S}(\mathrm{Cys})$ and $\mathrm{Se}(\mathrm{Sec})$ is decreased to 2.47 and $2.57 \AA$, respectively, in PCs (Figure 3). Strong H-bondings are also observed in PCs between the leaving aqua ligand and the amine group of $\mathrm{Cys}$ or Sec, ranging from 1.93 to $2.06 \AA$ as mentioned in Figure 3. In PCs, the Au-S(Cys) bond distances in the case of mono- and di-Cys complexes of $\mathrm{Au}(\mathrm{III})$ are calculated to be 2.47 and $2.51 \AA$, while $\mathrm{Au}-\mathrm{Se}(\mathrm{Sec})$ bond lengths in the case of mono-Sec and di-Sec complexes are observed to be 2.57 and $2.59 \AA$, respectively.

2.1.3. Interaction of Aquated $\boldsymbol{R}^{\prime}$ Complexes with Cys and Sec. The interaction of $\mathbf{R}^{\prime}$ with the $S$ site of Cys and Se site of Sec is found to be quite similar to the interaction of aquated $\mathbf{R}$ with Cys and Sec (Scheme 3). Step-3' shows the substitution of the aqua ligand from $\left[\mathrm{Au}(\operatorname{damp})\left(\mathrm{H}_{2} \mathrm{O}\right) \mathrm{Cl}\right]^{+}\left(\mathbf{P}-\mathbf{1}^{\prime}\right)$ with Cys, while Step-4' represents the substitution of the aqua ligand in $\mathbf{P}$ $\mathbf{1}^{\prime}$ with Sec. The substitution of aqua ligands of [Au(damp)$\left.\left(\mathrm{H}_{2} \mathrm{O}\right)_{2}\right]^{2+}\left(\mathbf{P}-2^{\prime}\right)$ with Cys leads to the formation of $\left[\mathrm{Au}(\text { damp })\left(\mathrm{H}_{2} \mathrm{O}\right) \mathrm{Cys}\right]^{2+}\left(\mathbf{P}-5^{\prime}\right)$ in Step-5' and $[\mathrm{Au}($ damp $)-$ $\left.(\mathrm{Cys})_{2}\right]^{2+}\left(\mathbf{P}-7^{\prime}\right)$ in Step-7'. Similarly, $\left[\mathrm{Au}(\text { damp })\left(\mathrm{H}_{2} \mathrm{O}\right) \mathrm{Sec}\right]^{2+}$ $\left(\mathbf{P}-6^{\prime}\right)$ and $\left[\mathrm{Au}(\mathrm{damp})(\mathrm{Sec})_{2}\right]^{2+}\left(\mathbf{P}-\mathbf{8}^{\prime}\right)$ are formed in Step-6' and Step- $\mathbf{8}^{\prime}$, respectively. The lowest-energy geometries of all of the stationary points involved in the interaction of mono- and diaquated $\mathrm{Au}(\mathrm{III})$ complexes with $\mathrm{Cys}$ and $\mathrm{Sec}$ are shown in Figure 4, while their important structural parameters are presented in Table S3.

In the case of complex $\mathbf{R}^{\prime}$ also, H-bonding is noticed between the hydrogen atom of the aqua ligand and the nitrogen and sulfur atoms of Cys or nitrogen and selenium of Sec in RCs. The Hbonding distances in RCs, PCs, and TSs are found to be in the range of 1.62-2.48 $\AA$. As shown in Figure 4, the transition states represent the simultaneous breaking of $\mathrm{Au}-\mathrm{O}\left(\mathrm{H}_{2} \mathrm{O}\right)$ and the formation of $\mathrm{Au}-\mathrm{S}(\mathrm{Cys}) / \mathrm{Au}-\mathrm{Se}(\mathrm{Sec})$ bonds. The $\mathrm{Au}-\mathrm{S}$ (Cys) $/ \mathrm{Se}(\mathrm{Sec})$ bond length is in the range of $2.99-3.16 \AA$, while the $\mathrm{Au}-\mathrm{O}\left(\mathrm{H}_{2} \mathrm{O}\right)$ bond length is calculated to be in the range of 2.26-2.51 $\AA$ in the TSs. It is noticed from Figure 4 that in the case of PCs, the aqua ligands are released from $\mathrm{Au}(\mathrm{III})$; however, they remain attached to the complex through $\mathrm{H}$ bonding with coordinated $\mathrm{Cys}$ or Sec. The $\mathrm{Au}-\mathrm{S}(\mathrm{Cys})$ and $\mathrm{Au}-\mathrm{Se}(\mathrm{Sec})$ bond lengths in the case of $\left[\mathrm{Au}(\mathrm{damp})\left(\mathrm{H}_{2} \mathrm{O}\right)\right.$ $\mathrm{Cys}]^{+}$and $\left[\mathrm{Au}(\text { damp })\left(\mathrm{H}_{2} \mathrm{O}\right) \mathrm{Sec}\right]^{+}$are found to be 2.64 and 2.75 $\AA$, respectively. On the other hand, the $\mathrm{Au}-\mathrm{S}(\mathrm{Cys})$ and $\mathrm{Au}-$ $\mathrm{Se}(\mathrm{Sec})$ bond distances are observed to lie in the range of 2.452.63 and 2.55-2.72 $\AA$ for $\left[\mathrm{Au}(\mathrm{damp})(\mathrm{Cys})_{2}\right]^{2+}$ and $[\mathrm{Au}-$ $($ damp $\left.)(\mathrm{Sec})_{2}\right]^{2+}$, respectively.

2.2. Energy Profiles. The measure of the activation free energy of a chemical reaction can predict its feasibility. The lower the activation energy barrier, the faster the rate of the reaction. In this study, activation energies have been computed by the DFT method, utilizing the CPCM solvation model in aqueous medium. The relative Gibbs free energy $(\Delta G)$ and change of enthalpy $(\Delta H)$ for the hydrolysis of $\mathbf{R}$ and $\mathbf{R}^{\prime}$ and their interaction with biomolecules have been calculated at the B3LYP/(LanL2DZ/6-311G++(3df,2pd)) level of theory, and the energetics is explained in detail in the following sections.

2.2.1. Hydrolysis of $R$ and $R^{\prime}$. Herein, the activation energy barrier $(\mathrm{kcal} / \mathrm{mol})$ and enthalpy change for the first and second hydrolysis of $\mathbf{R}$ and $\mathbf{R}^{\prime}$ are evaluated by the DFT method; the calculated values are illustrated in Table 1 and energy profile diagrams are shown in Figure 5. Table S4 reveals that the first and second hydrolysis reactions of $\mathbf{R}$ and $\mathbf{R}^{\prime}$ are endothermic. The activation free energy for the first chlorido ligand hydrolysis of complex $\mathbf{R}$ is higher by $4.3 \mathrm{kcal} / \mathrm{mol}$ than that of $\mathbf{R}^{\prime}$. Activation free energies for the first hydrolysis of $\mathbf{R}$ and $\mathbf{R}^{\prime}$ are computed to be 15.7 and $11.4 \mathrm{kcal} / \mathrm{mol}$, respectively. Thus, 
Step-3' : Interaction of P-1' with Cys
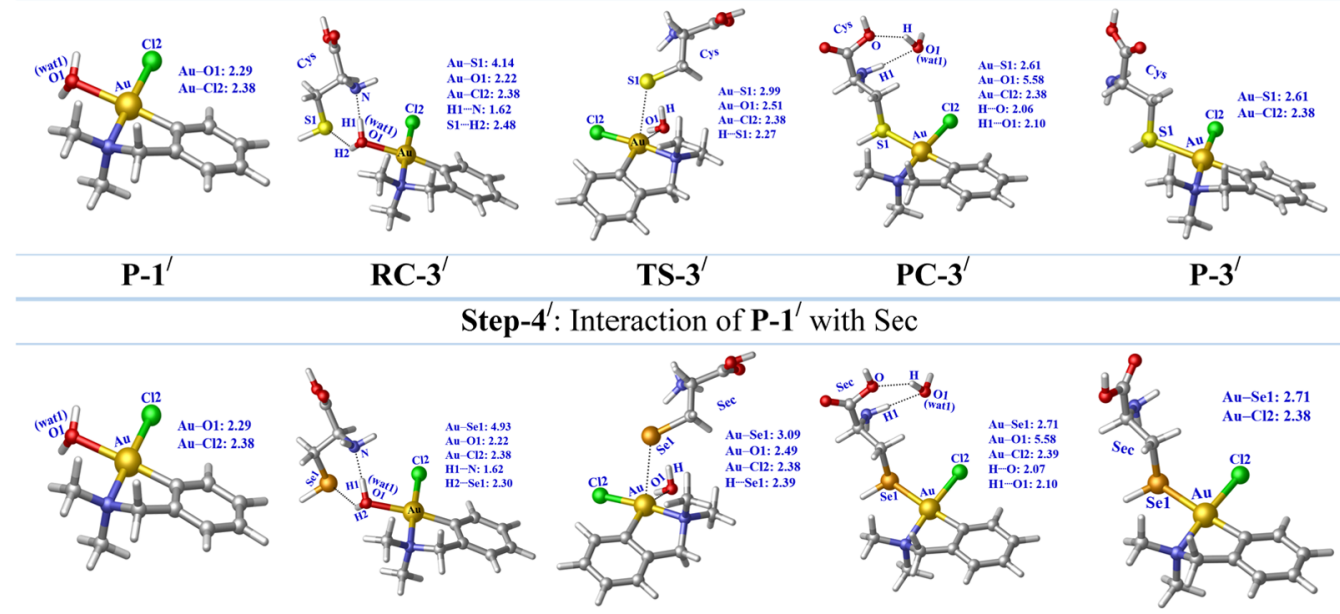

\section{TS-3'}

\section{PC-3}

P-3'

tep-4 ${ }^{\prime}$ : Interaction of $\mathbf{P}-\mathbf{1}^{\prime}$ with Sec

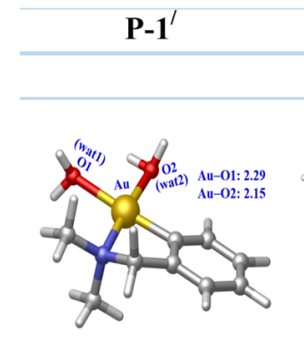

RC-4'
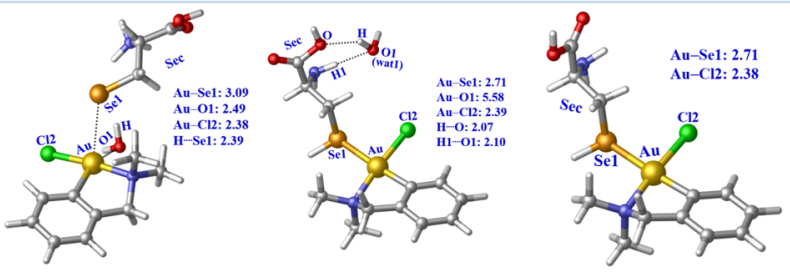

Step-5: Interaction of $\mathbf{P - 2}{ }^{\prime}$ with Cys

\section{PC-4}
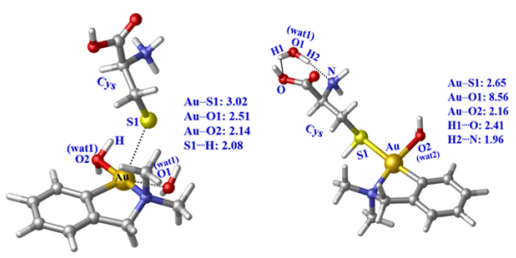

PC-5

TS-5'

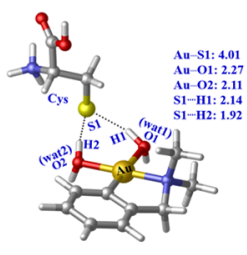

RC-5

Step-6 ${ }^{\prime}$ : Interaction of $\mathbf{P - 2}{ }^{\prime}$ with $\mathrm{Sec}$
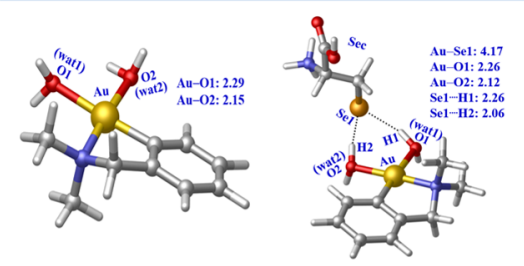

\section{P-4}
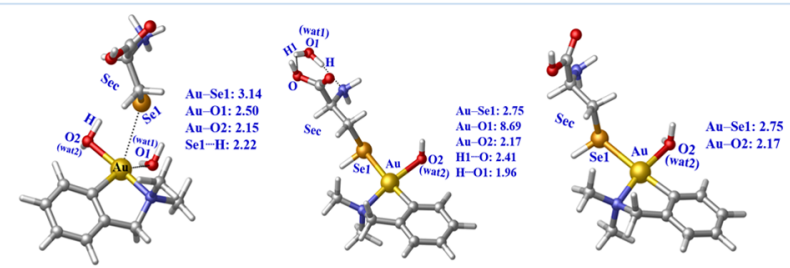

P-2

RC-6'

TS-6'

PC-6

P-6

Step-7 ${ }^{\prime}$ : Interaction of $\mathbf{P - 5} \mathbf{5}^{\prime}$ with Cys

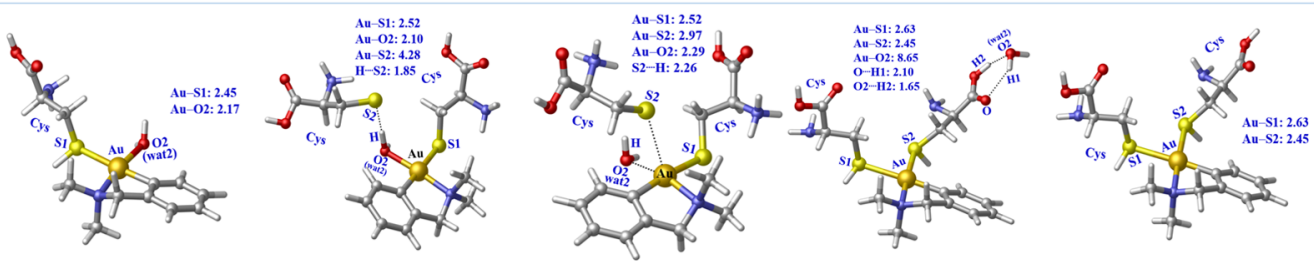

P-5

RC-7'

TS-7

PC-7'

P-7

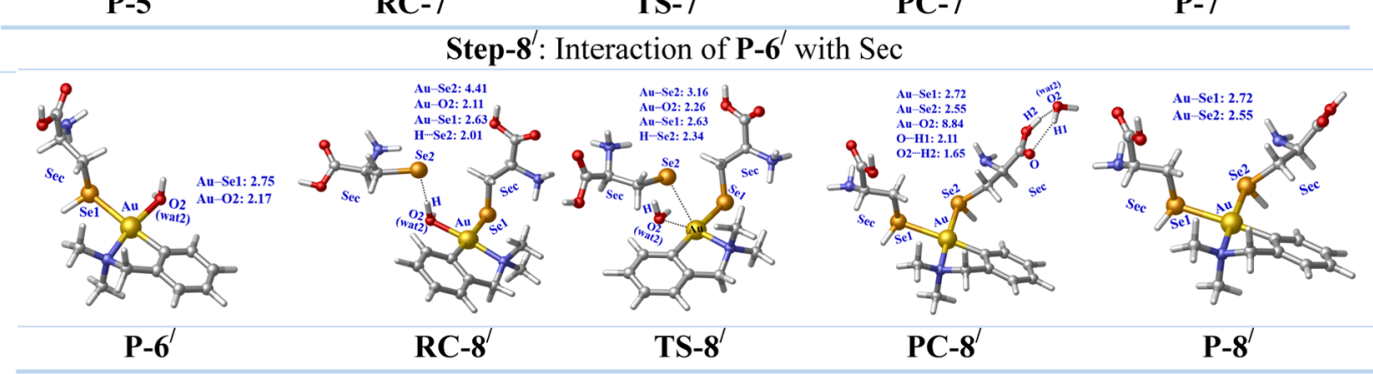

Figure 4. Optimized structures of all of the stationary points involved in the interaction of aquated $\mathbf{R}^{\prime}$ complexes with $\mathbf{C y s}$ and Sec, calculated at $\mathrm{B} 3 \mathrm{LYP} /(\mathrm{LanL} 2 \mathrm{DZ} / 6-31 \mathrm{G}(\mathrm{d}, \mathrm{p}))$ in aqueous medium. Bond distances are expressed in units of $\AA$.

faster aquation is observed in the case of complex $\mathbf{R}^{\prime}$ due to the

presence of a comparatively more labile chlorido ligand and the trans effect of the 2-[(dimethylamino)methyl $]$ phenyl (damp)

group. 
Table 1. Calculated Rate Constant Values $\left(k\right.$ in $\left.\mathrm{s}^{-1}\right)$ for Each Hydrolysis Step of $\mathbf{R}$ and $\mathbf{R}^{\prime}$ in Aqueous Medium

\begin{tabular}{lc}
\multicolumn{1}{c}{ reaction } & rate constant $\left.(k \text { in s})^{-1}\right)$ \\
$\mathrm{R}+\mathrm{H}_{2} \mathrm{O} \rightarrow \mathrm{P}-1+\mathrm{Cl}^{-}$ & $1.92 \times 10^{1}$ \\
$\mathrm{P}-1+\mathrm{H}_{2} \mathrm{O} \rightarrow \mathrm{P}-2+\mathrm{Cl}^{-}$ & $5.62 \times 10^{2}$ \\
$\mathrm{R}^{\prime}+\mathrm{H}_{2} \mathrm{O} \rightarrow \mathrm{P}-1^{\prime}+\mathrm{Cl}^{-}$ & $2.73 \times 10^{4}$ \\
$\mathrm{P}-1^{\prime}+\mathrm{H}_{2} \mathrm{O} \rightarrow \mathrm{P}-2^{\prime}+\mathrm{Cl}^{-}$ & $2.90 \times 10^{5}$
\end{tabular}

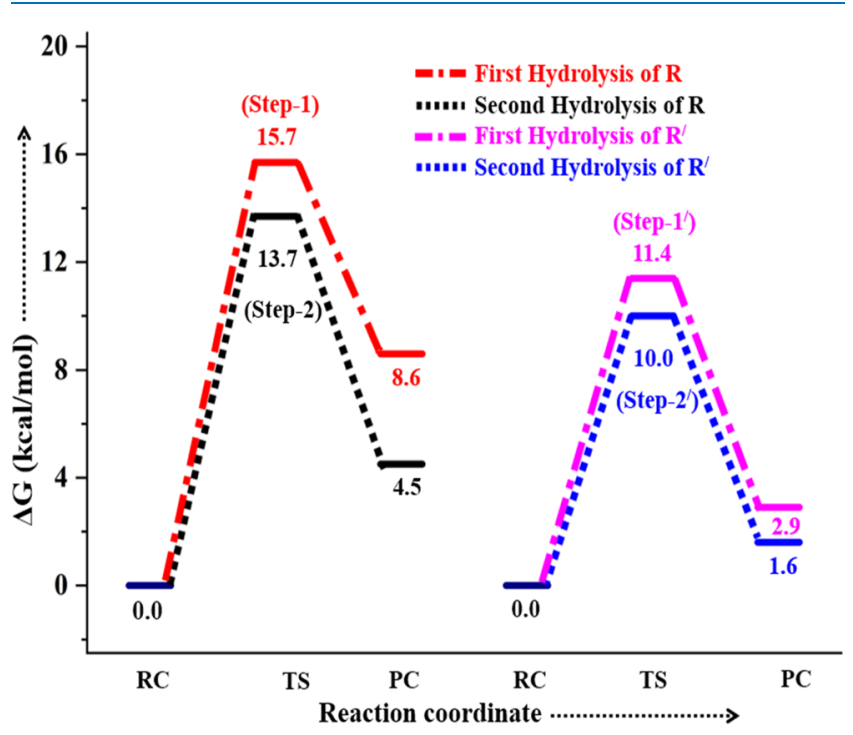

Figure 5. Relative Gibbs free energy $(\mathrm{kcal} / \mathrm{mol})$ profiles for the hydrolysis of $\mathbf{R}$ and $\mathbf{R}^{\prime}$ in aqueous medium.

However, the second hydrolysis of $\mathbf{R}^{\prime}$ (Step- $\mathbf{2}^{\prime}$ ) for the formation of the diaquated complex PC-2' also exhibits a lower activation energy barrier $(10.0 \mathrm{kcal} / \mathrm{mol})$ in comparison to the second hydrolysis of $\mathbf{R}$ (Step-2) $(13.7 \mathrm{kcal} / \mathrm{mol})$. An interesting observation is that the second hydrolysis of $\mathbf{R}$ as well as $\mathbf{R}^{\prime}$ is more favorable, which may be due to the increased electrophilic character of $\mathrm{Au}(\mathrm{III})$. The increased electrophilic character is because of the lower possibility of ligand-to-metal charge transfer. A similar result is found with the theoretical data available in the case of hydrolysis of cisplatin. ${ }^{50}$ Therefore, the second hydrolysis of $\mathbf{R}$ and $\mathbf{R}^{\prime}$ is kinetically as well as thermodynamically more favorable. The activation Gibbs free energies evaluated by DFT for the first and second hydrolysis of $\mathbf{R}$ and $\mathbf{R}^{\prime}$ are found to be relatively lower in comparison to cisplatin $(22.9$ and $26.2 \mathrm{kcal} / \mathrm{mol}$ for first and second hydrolysis, respectively) and other platinum-based anticancer drugs. ${ }^{51,52}$

2.2.2. Interactions of Aquated R Complexes with Cys and Sec. The Gibbs free energies and enthalpies of all of the stationary points for the substitution of aqua ligands of monoand diaquated $\mathbf{R}$ and $\mathbf{R}^{\prime}$ with $\mathbf{C y s}$ and Sec are computed by the DFT method at B3LYP/(LanL2DZ/6-31G(d,p)) level. The relative Gibbs energy profile diagram and calculated results are shown in Figure 6 and Table S5, respectively. Figure 6 shows that the activation free energies for the interaction of Cys and Sec with mono- and diaquated complexes (P-1), (P-2), (P-5), and (P-6) are in the order P-1 $>\mathbf{P}-\mathbf{2}>\mathbf{P}-\mathbf{5}>\mathbf{P}-\mathbf{6}$. Moreover, a lower activation energy barrier is observed in the interaction of Sec with the aquated complexes of $\mathbf{R}$ compared to the interaction of Cys, because of the superior nucleophilicity of the Se sites of Sec. The activation energy barrier for the interaction of Cys with P-1 is evaluated to be $10.6 \mathrm{kcal} / \mathrm{mol}$ (Step-3), whereas the corresponding value in the case of Sec is $8.1 \mathrm{kcal} / \mathrm{mol}$ (Step-4). Figure 6 also shows that the substitution reactions of aqua ligands from mono- as well as diaquated complexes of $\mathbf{R}$ with Sec to form mono- and di-Sec complexes are exothermic (negative $\Delta H$ ), whereas the formation of monoand di-Cys complexes is observed to be endothermic (positive $\Delta H$ ) (Table 2). On the other hand, the formation of P-7 and P-8 is thermodynamically more favorable and the corresponding activation free energy values are 9.3 (Step-7) and $7.3 \mathrm{kcal} / \mathrm{mol}$ (Step-8), respectively.

2.2.3. Interactions of Aquated $\boldsymbol{R}^{\prime}$ Complexes with Cys and $\mathrm{Sec}$. In this section, the energy profile diagram for the interaction of the $S$ site of Cys and Se site of Sec with P-1' ${ }^{\prime}$ and P-2' has been analyzed in detail. The energy profile diagram evaluated by DFT for these reactions is displayed in Figure 7 and the calculated results are depicted in Table S6. It is seen from Figure 7 that the activation free energies for the interaction of the $\mathbf{S}$ site of Cys with $\mathbf{P}-\mathbf{1}^{\prime}$ and $\mathbf{P}-\mathbf{2}^{\prime}$ are 13.1 and $11.0 \mathrm{kcal} / \mathrm{mol}$, while the corresponding activation energies for the interaction of the $\mathbf{S e}$ site of Sec are 11.1 and $10.4 \mathrm{kcal} / \mathrm{mol}$, respectively. Lower

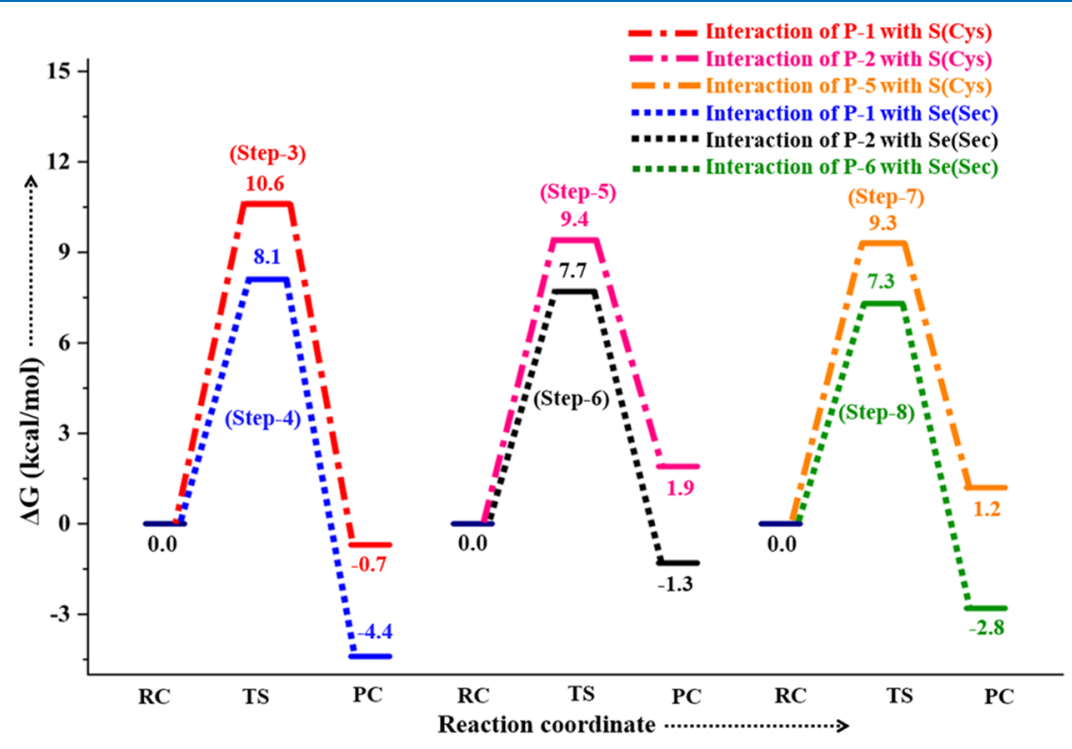

Figure 6. Relative Gibbs free energy (kcal/mol) profiles for the interaction of aquated $\mathbf{R}$ complexes with Cys and Sec in aqueous medium. 
Table 2. Calculated Rate Constant Values $\left(k\right.$ in $\left.\mathrm{s}^{-1}\right)$ for the Interaction of Aquated $\mathrm{R}$ and $\mathrm{R}^{\prime}$ Complexes with Cys and Sec in Aqueous Medium

\begin{tabular}{cc} 
reaction & rate constant $\left(k\right.$ in s$\left.^{-1}\right)$ \\
$\mathrm{P}-1+\mathrm{S}(\mathrm{Cys}) \rightarrow \mathrm{P}-3+\mathrm{H}_{2} \mathrm{O}$ & $1.05 \times 10^{5}$ \\
$\mathrm{P}-1+\mathrm{Se}(\mathrm{Sec}) \rightarrow \mathrm{P}-4+\mathrm{H}_{2} \mathrm{O}$ & $7.17 \times 10^{6}$ \\
$\mathrm{P}-2+\mathrm{S}(\mathrm{Cys}) \rightarrow \mathrm{P}-5+\mathrm{H}_{2} \mathrm{O}$ & $7.98 \times 10^{5}$ \\
$\mathrm{P}-2+\mathrm{Se}(\mathrm{Sec}) \rightarrow \mathrm{P}-6+\mathrm{H}_{2} \mathrm{O}$ & $1.41 \times 10^{7}$ \\
$\mathrm{P}-5+\mathrm{S}(\mathrm{Cys}) \rightarrow \mathrm{P}-7+\mathrm{H}_{2} \mathrm{O}$ & $9.45 \times 10^{5}$ \\
$\mathrm{P}-6+\mathrm{Se}(\mathrm{Sec}) \rightarrow \mathrm{P}-8+\mathrm{H}_{2} \mathrm{O}$ & $2.77 \times 10^{7}$ \\
$\mathrm{P}-1^{\prime}+\mathrm{S}(\mathrm{Cys}) \rightarrow \mathrm{P}-3^{\prime}+\mathrm{H}_{2} \mathrm{O}$ & $1.62 \times 10^{3}$ \\
$\mathrm{P}-1^{\prime}+\mathrm{Se}(\mathrm{Sec}) \rightarrow \mathrm{P}-4^{\prime}+\mathrm{H}_{2} \mathrm{O}$ & $4.53 \times 10^{4}$ \\
$\mathrm{P}-2^{\prime}+\mathrm{S}(\mathrm{Cys}) \rightarrow \mathrm{P}-5^{\prime}+\mathrm{H}_{2} \mathrm{O}$ & $5.36 \times 10^{4}$ \\
$\mathrm{P}-2^{\prime}+\mathrm{Se}(\mathrm{Sec}) \rightarrow \mathrm{P}-6^{\prime}+\mathrm{H}_{2} \mathrm{O}$ & $1.48 \times 10^{5}$ \\
$\mathrm{P}-5^{\prime}+\mathrm{S}(\mathrm{Cys}) \rightarrow \mathrm{P}-7^{\prime}+\mathrm{H}_{2} \mathrm{O}$ & $1.57 \times 10^{6}$ \\
$\mathrm{P}-6^{\prime}+\mathrm{Se}(\mathrm{Sec}) \rightarrow \mathrm{P}-8^{\prime}+\mathrm{H}_{2} \mathrm{O}$ & $2.34 \times 10^{7}$ \\
\hline
\end{tabular}

activation energies are recorded in the cases of the formation of $\mathbf{P}-\mathbf{7}^{\prime}(9.0 \mathrm{kcal} / \mathrm{mol})$ and $\mathbf{P}-\mathbf{8}^{\prime}(7.4 \mathrm{kcal} / \mathrm{mol})$. Therefore, the formation of $\mathbf{P}-\mathbf{7}^{\prime}$ and $\mathbf{P}-\mathbf{8}^{\prime}$ is noticed to be thermodynamically as well as kinetically more favorable than the formation of $\mathbf{P}-\mathbf{5}^{\prime}$ and $\mathbf{P}-\mathbf{6}^{\prime}$. The enthalpy changes $(\Delta H)$ for the aqua substitution reaction of mono- and diaquated $\mathbf{R}^{\prime}$ with $\mathbf{C y s}$ and $\mathbf{S e c}$ are found to be endothermic. Notably, the aqua complexes of $\mathbf{R}^{\prime}$ binding to Sec are kinetically more favorable, because of their lower Gibbs free energy of activation.

2.3. Kinetic Analysis. The rate constant values $(k)$ for the hydrolysis of $\mathbf{R}$ and $\mathbf{R}^{\prime}$ computed with the transition state theory formalism using the Eyring equation (eq 1) are summarized in Table 1. Subsequently, the rate constant values are also evaluated for the aqua ligand exchange reactions of mono- and diaquated $\mathbf{R}$ and $\mathbf{R}^{\prime}$ with Cys and Sec (Table 2). Both the first and second hydrolysis of $\mathbf{R}$ and $\mathbf{R}^{\prime}$ complexes are seen to follow pseudo-first-order kinetics. The rate constant values for hydrolysis of P-1 and P-1' are calculated to be $5.62 \times 10^{2}$ and $2.90 \times 10^{5} \mathrm{~s}^{-1}$, respectively, which are greater than the values for the hydrolysis of $\mathbf{R}$ and $\mathbf{R}^{\prime}$ (Table 1), showing that the second hydrolysis of the $\mathrm{Au}$ (III) complexes takes place instantaneously. From Table 2, it is seen that diaquated Au(III) complexes show more propensity to interact with their target, i.e., Cys and Sec, with a faster rate than that of monoaquated $\mathrm{Au}$ (III) complexes.
Furthermore, the rate constant values evaluated by DFT reveal that formation of mono- and di-Sec $\mathrm{Au}$ (III) complexes P-8 and $\mathbf{P - \mathbf { 8 } ^ { \prime }}$ is faster than the formation of di-Cys $\mathrm{Au}(\mathrm{III})$ complexes $\mathbf{P}$ 7 and $\mathbf{P}-\mathbf{7}^{\prime}$. The DFT-derived rate constant value for the formation of $\left[\mathrm{Au}(\mathrm{DMDT})(\mathrm{Sec})_{2}\right]^{2+}$ from $\left[\mathrm{Au}(\mathrm{DMDT})\left(\mathrm{H}_{2} \mathrm{O}\right)\right.$ $\mathrm{Sec}]^{2+}$ is $2.77 \times 10^{7} \mathrm{~s}^{-1}$, while that for the formation of $\left[\mathrm{Au}(\text { damp })(\mathrm{Sec})_{2}\right]^{2+}$ from $\left[\mathrm{Au}(\text { damp })\left(\mathrm{H}_{2} \mathrm{O}\right) \mathrm{Sec}\right]^{2+}$ is $2.34 \times$ $10^{7} \mathrm{~s}^{-1}$. Therefore, the formation of $\left[\mathrm{Au}(\mathrm{DMDT})(\mathrm{Sec})_{2}\right]^{2+}$ is more favorable than the formation of $\left[\mathrm{Au}(\mathrm{damp})(\mathrm{Sec})_{2}\right]^{2+}$.

2.4. Electronic Characteristics. Natural population analysis (NPA) has been performed on the important atoms of all of the stationary points involved in the hydrolysis as well as the interaction of biomolecules of $\mathbf{R}$ and $\mathbf{R}^{\prime}$ to realize the significant variation of net atomic charges. In particular, the maximum variation of net atomic charges is observed on central $\mathrm{Au}(\mathrm{III}), \mathrm{Cl}, \mathrm{O}\left(\mathrm{H}_{2} \mathrm{O}\right)$, and $\mathrm{S}(\mathrm{Cys})$ or $\mathrm{Se}(\mathrm{Sec})$ atoms. The charge redistribution on the important atoms is summarized in Tables S7-S9 and schematically presented in Figure 8. During the chlorido ligand hydrolysis in the cases of $\mathbf{R}$ and $\mathbf{R}^{\prime}$, the positive charge on the gold atom is found to be decreased in reactant intermediates (RCs) and finally increased in the formation of products $(\mathbf{P})$. This phenomenon is attributed to the relatively stronger $\sigma$ and $\pi$ donor ability of the chlorido ligand in comparison to the aqua ligand, facilitating the ligand-to-metal charge transfer (LMCT). On the contrary, the net atomic charge on gold is dramatically decreased on substitution of the aqua ligand by Cys or Sec. These findings suggest that the decrease of the net positive charge on the gold atom is due to the acceptance of considerable negative charges from the $\mathrm{S}$ atom of Cys or Se atom of Sec. On the other hand, the leaving chlorido ligand gains an electron density of 0.432 lel in PCs during the hydrolysis of the parent gold complexes. Similarly, the net negative charge on the oxygen atom of the incoming aqua ligand decreases up to 0.090 lel because of the transfer of negative charge to gold to form a stable aquated $\mathrm{Au}$ (III) complex (Figure 8). Furthermore, with the approach of Cys and Sec toward the central gold during the aqua ligand exchange reactions, S (Cys) and $\mathrm{Se}(\mathrm{Sec})$ atoms develop a net positive charge due to the ligand-to-metal charge transfer. In contrast, the net charge on the oxygen atom of the leaving water molecule drastically increases in PCs. That is, charge redistribution among the atoms is observed during the

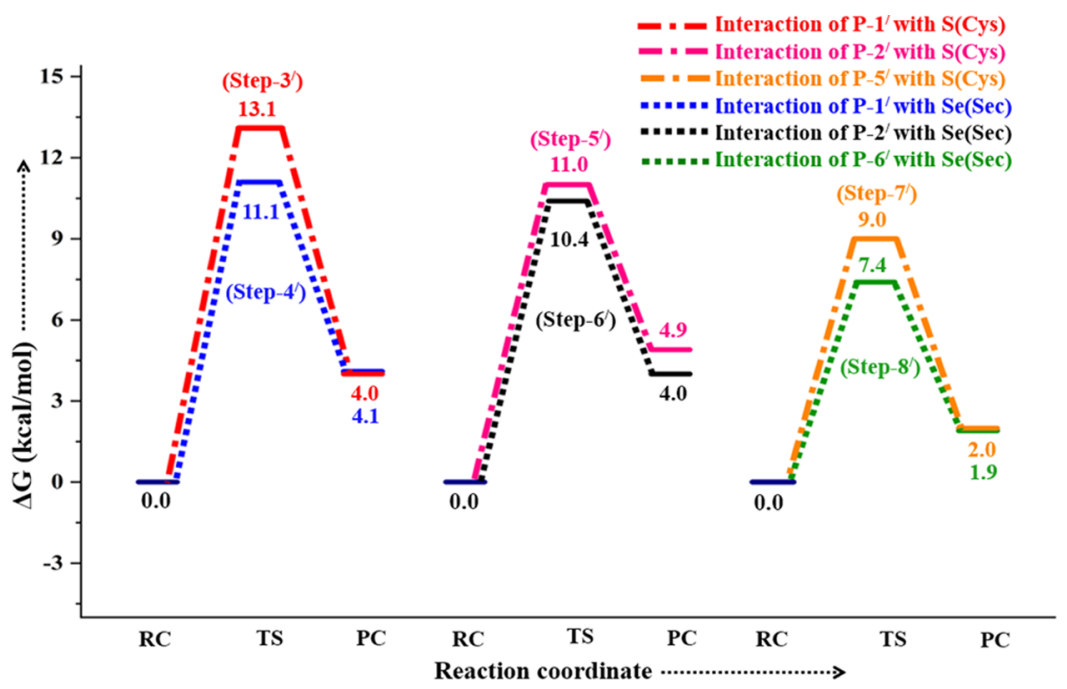

Figure 7. Relative Gibbs free energy (kcal/mol) profiles for the interaction of aquated $\mathbf{R}^{\prime}$ complexes with Cys and Sec in aqueous medium. 

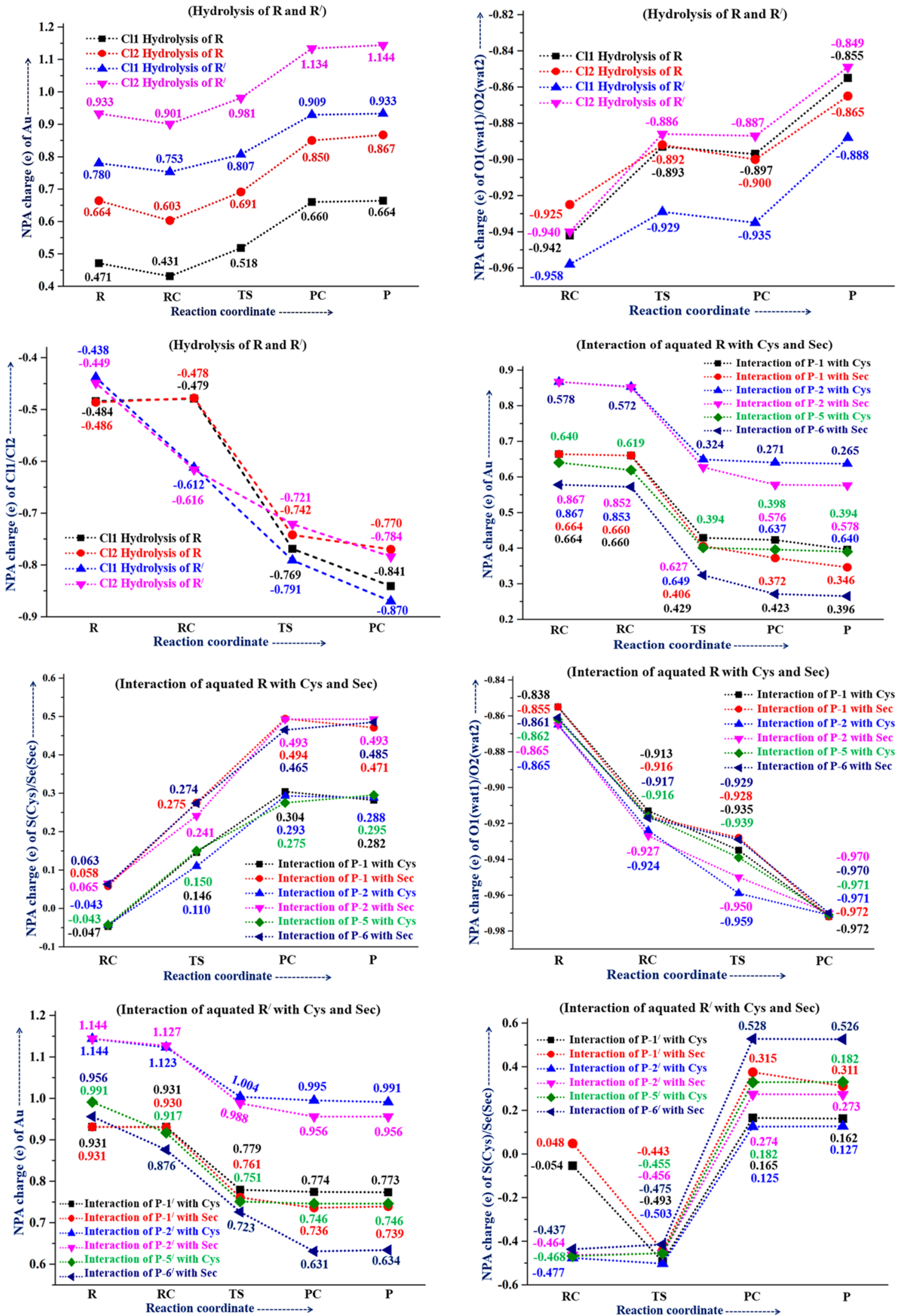

Figure 8. continued 


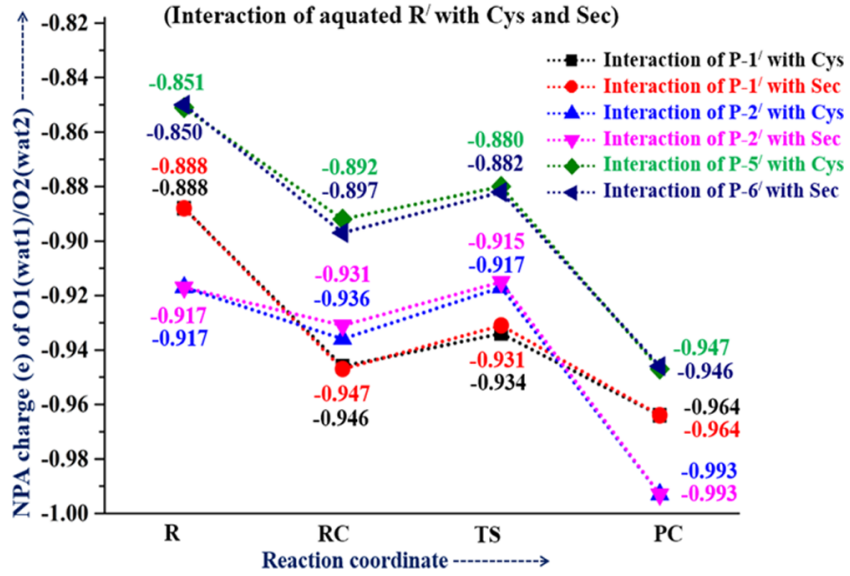

Figure 8. NPA charges on the central Au atom, $\mathrm{O}\left(\mathrm{H}_{2} \mathrm{O}\right), \mathrm{S}(\mathrm{Cys}) / \mathrm{Se}(\mathrm{Sec})$, and $\mathrm{Cl}$ atoms involved in each ligand substitution reaction step of $\mathbf{R}$ and $\mathbf{R}^{\prime}$.

processes of hydrolysis of $\mathrm{Au}(\mathrm{III})$ complexes and their interaction with biomolecules such as Cys and Sec.

2.5. Conceptual Density Functional Theory (CDFT) Analysis. The stability and chemical reactivity of the two $\mathrm{Au}$ (III) complexes $\mathbf{R}$ and $\mathbf{R}^{\prime}$ along with their aquated complexes have been successfully analyzed by employing the conceptual density functional theory (CDFT). The calculated chemical potential $(\mu)$, chemical hardness $(\eta)$, and electrophilicity index $(\omega)$ values are depicted in Table 3 . On the other hand, the

Table 3. Energies of HOMO ( $E_{\mathrm{H}}$ in $\left.\mathrm{eV}\right)$ and LUMO $\left(E_{\mathrm{L}}\right.$ in $\mathrm{eV})$, Chemical Potential $(\boldsymbol{\mu}$ in eV), Chemical Hardness ( $\boldsymbol{\eta}$ in $\mathrm{eV})$, and Electrophilicity Index $(\omega$ in $\mathrm{eV})$ of $\mathbf{R}$ and $\mathrm{R}^{\prime}$ along with Their Aquated Species

\begin{tabular}{ccccccc} 
complex & $E_{\mathrm{H}}$ & $E_{\mathrm{L}}$ & $\Delta E$ & $\mu$ & $\eta$ & $\omega$ \\
\hline $\mathbf{R}$ & -7.533 & -4.277 & 3.256 & -5.905 & 1.628 & 10.709 \\
$\mathbf{P}-1$ & -7.842 & -4.737 & 3.105 & -6.290 & 1.553 & 12.740 \\
$\mathbf{P - 2}$ & -8.233 & -5.180 & 3.053 & -6.707 & 1.527 & 14.732 \\
$\mathbf{R}^{\prime}$ & -7.170 & -3.307 & 3.863 & -5.239 & 1.932 & 7.104 \\
P-1' $^{\prime}$ & -7.445 & -3.624 & 3.821 & -5.534 & 1.911 & 8.016 \\
P-2' $^{\prime}$ & -7.698 & -4.140 & 3.558 & -5.919 & 1.779 & 9.847
\end{tabular}

energy gap $(\Delta E)$ between LUMO $\left(E_{\mathrm{L}}\right)$ and HOMO $\left(E_{\mathrm{H}}\right)$ has also been determined to identify the chemical stability of the gold complexes. As shown in Table 3 , the calculated $\Delta E$ values of the complex $\mathbf{R}^{\prime}$ and their hydrolyzed products are found to vary in the order $\left[\mathrm{Au}(\right.$ damp $\left.) \mathrm{Cl}_{2}\right]>\left[\mathrm{Au}(\text { damp })\left(\mathrm{H}_{2} \mathrm{O}\right) \mathrm{Cl}\right]^{+}>$ $\left[\mathrm{Au}(\text { damp })\left(\mathrm{H}_{2} \mathrm{O}\right)_{2}\right]^{2+}$. A similar order for the $\Delta E$ values is also noticed in the cases of $\mathbf{R}$ and their hydrolyzed products, i.e., $\left[\mathrm{Au}(\mathrm{DMDT}) \mathrm{Cl}_{2}\right]>\left[\mathrm{Au}(\mathrm{DMDT})\left(\mathrm{H}_{2} \mathrm{O}\right) \mathrm{Cl}\right]^{+}>[\mathrm{Au}(\mathrm{DMDT})-$ $\left.\left(\mathrm{H}_{2} \mathrm{O}\right)_{2}\right]^{2+}$. Therefore, the parent complexes $\mathbf{R}(\Delta E=3.256 \mathrm{eV})$ and $\mathbf{R}^{\prime}(\Delta E=3.863 \mathrm{eV})$ are the least reactive (more stable) in comparison to their hydrolyzed complexes. Again, the stability of a chemical species can also be determined in terms of its chemical hardness $(\eta)$. The larger the value of chemical hardness, the higher its stability. ${ }^{53}$ Hence, the calculated chemical hardness values imply that the chlorido complexes $\mathbf{R}$ $(\eta=1.628 \mathrm{eV})$ and $\mathbf{R}^{\prime}(\eta=1.9315 \mathrm{eV})$ are the most stable. On the other hand, a higher electrophilicity index $(\omega)$ is calculated for diaqua complexes P-2 $(\omega=14.732)$ and P-2' $(\omega=9.847)$. Therefore, $\mathbf{P}-\mathbf{2}$ and $\mathbf{P}-\mathbf{2}^{\prime}$ display a relatively better electrophilicity, and hence, they can interact effectively with biomolecules (i.e., with $\mathrm{Cys}$ and $\mathrm{Sec}$ ). The calculated rate constant values also exhibited similar reactivity trends. Similarly, the specific reactivity of the diaquated ruthenium complex, namely ICR, is found to be more effective with DNA bases and protein residues in comparison to the mono-aqua complex. ${ }^{54}$

\section{CONCLUSIONS}

In summary, this research presents a detailed mechanistic investigation on the hydrolysis of two potential anticancer drugs, $\left[\mathrm{Au}(\mathrm{DMDT}) \mathrm{Cl}_{2}\right]$ (DMDT $=N, N$-dimethyldithiocarbamate) (R) and $\left[\mathrm{Au}(\right.$ damp $\left.) \mathrm{Cl}_{2}\right]$ (damp = 2-[(dimethylamino $)$ methyl $]$ phenyl) ( $\left.\mathbf{R}^{\prime}\right)$, and their interaction with protein residues such as Cys and Sec using the density functional theory (DFT) approach. The optimized geometries of the $\mathrm{Au}$ (III) complexes suggest that hydrogen bonding plays a crucial role in stabilizing the stationary points in the process of hydrolysis, as well as their interaction with biomolecules. The ligand exchange reactions proceed through a pentacoordinated trigonal bipyramidal (TBP) transition state with a concerted dissociative interchange mechanism $\left(\mathbf{I}_{\mathbf{d}}\right)$. The calculated activation energy barriers revealed that the second hydrolysis step of both the complexes $\mathbf{R}$ $(\Delta G=13.7 \mathrm{kcal} / \mathrm{mol})$ and $\mathbf{R}^{\prime}(\Delta G=10.0 \mathrm{kcal} / \mathrm{mol})$ is kinetically more predominant, and their rate constant values are $5.62 \times 10^{2}$ and $2.90 \times 10^{5} \mathrm{~s}^{-1}$, respectively. The kinetic analysis indicates that the studied $\mathrm{Au}$ (III) complexes undergo instantaneous hydrolysis reaction in aqueous medium, with quite high pseudo-first-order rate constant values. The calculated activation free energy values show that the Se binding site of Sec is superior to the $S$ site of Cys in the case of aquated $\mathbf{R}$ and $\mathbf{R}^{\prime}$. Diaqua complexes $\mathbf{P}-\mathbf{2}$ and $\mathbf{P}-\mathbf{2}^{\prime}$ are observed to interact with Cys and Sec with a lower activation energy than that of cholroaqua complexes (P-1 and $\left.\mathbf{P}-\mathbf{1}^{\prime}\right)$. Again, it has been observed that the chloroaquated and diaquated complexes of $\mathbf{R}$ undergo faster aqua substitution reactions with Cys and Sec than the aquated complexes of $\mathbf{R}^{\prime}$. In particular, formation of diCys as well as di-Sec $\mathrm{Au}(\mathrm{III})-\mathrm{DMDT}$ or $\mathrm{Au}(\mathrm{III})-$ damp complexes from their corresponding mono-Cys and mono-Sec complexes is found to be kinetically more favorable. However, the conversion of $\mathbf{P}-\mathbf{6}$ to $\mathbf{P}-\mathbf{8}$ has been found to proceed with the lowest activation free energy of $7.3 \mathrm{kcal} / \mathrm{mol}$, having a rate constant value of $2.77 \times 10^{7} \mathrm{~s}^{-1}$. CDFT analysis confirmed that the diaquated P-2 and P-2' complexes are most electrophilic and exhibit a significantly strong interaction with Cys and Sec biomolecules. 
Furthermore, natural population analysis demonstrates the various charge distribution patterns in all of the optimized gold complexes, which in turn indicates the reaction progress. This theoretical investigation may provide a comprehensive mechanistic idea about the hydrolysis and biomolecular interactions of well-known anticancer drugs $\mathbf{R}$ and $\mathbf{R}^{\prime}$.

\section{COMPUTATIONAL METHODS}

DFT is progressively becoming an impactful computational tool in medicinal chemistry and drug designing. Herein, the hydrolysis mechanisms of $\mathbf{R}$ and $\mathbf{R}^{\prime}$ as well as their interaction with biomolecules (Cys and Sec) were investigated in the framework of DFT by employing Gaussian 09 software package. ${ }^{55}$ Optimization of all of the stationary points was done without imposing any symmetry constraints by utilizing the B3LYP ${ }^{56}$ functional, in combination with the effective core potential LanL2DZ ${ }^{57}$ basis set for $\mathrm{Au}$ atom and 6-31G(d,p) ${ }^{58}$ basis set for $\mathrm{C}, \mathrm{H}, \mathrm{N}, \mathrm{O}, \mathrm{S}$, and $\mathrm{Cl}$ atoms. The B3LYP functional comprises the Becke three-parameter hybrid exchange functional (B3) ${ }^{59}$ and Lee, Yang, and Parr correlation functional (LYP $)^{60}$ at the gradient-corrected density functional theory level. To incorporate the bulk effect of solvation on the optimized gas-phase geometry, an implicit conductor-like polarizable continuum solvation model (CPCM) with an dielectric constant of 78.39 was exploited at $298.15 \mathrm{~K}$ and 1 atm pressure. ${ }^{61}$ Harmonic vibrational frequency calculations were performed at the same level of theory to verify the nature of stationary points, and also thermal corrections to Gibbs free energies and enthalpies were incorporated. Each transition state was further confirmed by evaluating the intrinsic reaction coordinates (IRC). ${ }^{62}$ Single-point calculations (SP) were performed using the optimized solvent-phase geometry to obtain improved energy values at B3LYP/(LanL2DZ/6-311+ $+\mathrm{g}(3 \mathrm{df}, 2 \mathrm{pd}))$ level. $^{63}$ In addition, natural population analysis (NPA) ${ }^{64,65}$ was performed in order to understand the charge redistribution on the important atoms of the complexes. The rate constants $(k)$ of each step of the substitution reaction were evaluated at $T=298.15 \mathrm{~K}$ using the transition state theory proposed by Eyring $^{66}$ (eq 1).

$$
k(T)=\frac{k_{\mathrm{B}} T}{h} \mathrm{e}^{-\Delta G^{\ddagger} / R T}
$$

where $k_{\mathrm{B}}$ is the Boltzmann constant, $T$ is the absolute temperature, and $\Delta G^{\neq}$is the activation free energy.

Reactivity parameters such as chemical hardness $(\eta)$ and chemical potential $(\mu)$ were evaluated by adopting Koopman's approximation based on the nature of the highest occupied molecular orbital (HOMO) and the lowest unoccupied molecular orbital (LUMO). ${ }^{67}$

$$
\begin{aligned}
& \eta=\frac{1}{2}\left(E_{\mathrm{LUMO}}-E_{\mathrm{HOMO}}\right) \\
& \mu=\frac{1}{2}\left(E_{\mathrm{LUMO}}+E_{\mathrm{HOMO}}\right)
\end{aligned}
$$

The global electrophilicity index $(\omega)$ was defined by Parr et al. ${ }^{68}$ (eq 4)

$$
\omega=\frac{\mu^{2}}{2 \eta}
$$

where $E_{\mathrm{LUMO}}$ and $E_{\text {HOMO }}$ are the energies of LUMO and HOMO, respectively.

\section{ASSOCIATED CONTENT}

\section{(s) Supporting Information}

The Supporting Information is available free of charge at https://pubs.acs.org/doi/10.1021/acsomega.1c04168.

Cartesian coordinates of all of the relevant stationary points, Scheme S1, Tables S1-S10, and Figures S1-S3 (PDF)

\section{AUTHOR INFORMATION}

\section{Corresponding Author}

Paritosh Mondal - Department of Chemistry, Assam University, Silchar 788011 Assam, India; (1) orcid.org/00000003-1089-1620; Email: paritos_au@yahoo.co.in

\section{Authors}

Amit Kumar Pradhan - Department of Chemistry, Assam University, Silchar 788011 Assam, India; 이잉.org/00000002-5370-1332

Abhijit Shyam - Department of Chemistry, Assam University, Silchar 788011 Assam, India; 잉 orcid.org/0000-0002$1165-8567$

Complete contact information is available at:

https://pubs.acs.org/10.1021/acsomega.1c04168

\section{Notes}

The authors declare no competing financial interest.

\section{ACKNOWLEDGMENTS}

The authors are grateful to the Science and Engineering Research Board (SERB), New Delhi, India, for the financial support (File No. EEQ/2017/000480).

\section{REFERENCES}

(1) Rosenberg, B.; VanCamp, L.; Trosko, J. E.; Mansour, V. H. Platinum compounds: a new class of potent antitumour agents. Nature 1969, 222, 385-386.

(2) Zhou, L. Theoretical analysis on the transition state of the anticancer drug trans- $\left[\mathrm{PtCl}_{2}\right.$ (isopropylamine) $\left.{ }_{2}\right]$ and its cis isomer binding to DNA purine bases. J. Phys. Chem. B 2009, 113, 2110-2127.

(3) Jakupec, M. A.; Galanski, M.; Keppler, B. K. Tumour-Inhibiting Platinum Complexes-State of the Art and Future Perspectives. In Reviews of Physiology, Biochemistry and Pharmacology; Springer: Berlin, 2003; pp 1-53.

(4) Fuertes, M. A.; Alonso, C.; Pérez, J. M. Biochemical modulation of cisplatin mechanisms of action: enhancement of antitumor activity and circumvention of drug resistance. Chem. Rev. 2003, 103, 645-662.

(5) Perez, R. P. Cellular and Molecular Determinants of Cisplatin Resistance. Eur. J. Cancer 1998, 34, 1535-1542.

(6) Alberto, M. E.; Lucas, M. F.; Pavelka, M.; Russo, N. The degradation pathways in chloride medium of the third generation anticancer drug oxaliplatin. J. Phys. Chem. B 2008, 112, 10765-10768.

(7) Bruijnincx, P. C.; Sadler, P. J. New trends for metal complexes with anticancer activity. Curr. Opin. Chem. Biol. 2008, 12, 197-206.

(8) Ronconi, L.; Sadler, P. J. Using coordination chemistry to design new medicines. Coord. Chem. Rev. 2007, 251, 1633-1648.

(9) Ott, I.; Gust, R. Non platinum metal complexes as anti-cancer drugs. Arch. Pharm. 2007, 340, 117-126.

(10) Meggers, E. Exploring biologically relevant chemical space with metal complexes. Curr. Opin. Chem. Biol. 2007, 11, 287-292.

(11) Berners-Price, S. J.; Filipovska, A. Gold compounds as therapeutic agents for human diseases. Metallomics 2011, 3, 863-873.

(12) Rubbiani, R.; Kitanovic, I.; Alborzinia, H.; Can, S.; Kitanovic, A.; Onambele, L. A.; Stefanopoulou, M.; Geldmacher, Y.; Sheldrick, W. S.; Wolber, G.; Prokop, A.; Wölfl, S.; Ott, I. Benzimidazol-2-ylidene 
gold(I) complexes are thioredoxin reductase inhibitors with multiple antitumor properties. J. Med. Chem. 2010, 53, 8608-8618.

(13) Anestål, K.; Arnér, E. S. J. Rapid induction of cell death by selenium-compromised thioredoxin reductase 1 but not by the fully active enzyme containing selenocysteine. J. Biol. Chem. 2003, 278, $15966-15972$

(14) Marzano, C.; Gandin, V.; Folda, A.; Scutari, G.; Bindoli, A.; Rigobello, M. P. Inhibition of thioredoxin reductase by auranofin induces apoptosis in cisplatin-resistant human ovarian cancer cells. Free Radical Biol. Med. 2007, 42, 872-881.

(15) Ott, I. On the medicinal chemistry of gold complexes as anticancer drugs. Coord. Chem. Rev. 2009, 253, 1670-1681.

(16) Omondi, R. O.; Ojwach, S. O.; Jaganyi, D. Review of comparative studies of cytotoxic activities of $\mathrm{Pt}(\mathrm{II}), \mathrm{Pd}$ (II), $\mathrm{Ru}(\mathrm{II}) /(\mathrm{III})$ and $\mathrm{Au}(\mathrm{III})$ complexes, their kinetics of ligand substitution reactions and DNA/BSA interactions. Inorg. Chim. Acta 2020, 512, 119883-119897.

(17) Baddley, W. H.; Basolo, F. A Kinetic Study of Substitution Reactions of Some Gold (III) Complexes. Inorg. Chem. 1964, 3, 10871091

(18) Calamai, P.; Carotti, S.; Guerri, A.; Mazzei, T.; Messori, L.; Mini, E.; Orioli, P.; Speroni, G. P. Cytotoxic effects of gold (III) complexes on established human tumor cell lines sensitive and resistant to cisplatin. Anti-Cancer Drug Des. 1998, 13, 67-80.

(19) Nobili, S.; Mini, E.; Landini, I.; Gabbiani, C.; Casini, A.; Messori, L. Gold compounds as anticancer agents: chemistry, cellular pharmacology, and preclinical studies. Med. Res. Rev. 2010, 30, 550580.

(20) Pia Rigobello, M.; Messori, L.; Marcon, G.; Agostina Cinellu, M.; Bragadin, M.; Folda, A.; Scutari, G.; Bindoli, A. Gold complexes inhibit mitochondrial thioredoxin reductase: consequences on mitochondrial functions. J. Inorg. Biochem. 2004, 98, 1634-1641.

(21) Becker, K.; Gromer, S.; Schirmer, R. H.; Müller, S. Thioredoxin reductase as a pathophysiological factor and drug target. Eur. J. Biochem. 2000, 267, 6118-6125.

(22) Barnard, P. J.; Berners-Price, S. J. Targeting the mitochondrial cell death pathway with gold compounds. Coord. Chem. Rev. 2007, 251, 1889-1902.

(23) Mármol, I.; Quero, J.; Rodríguez-Yoldi, M.J.; Cerrada, E. Gold as a possible alternative to platinum-based chemotherapy for colon cancer treatment. Cancers 2019, 11, No. 780.

(24) Messori, L.; Marcon, G.; Orioli, P. Gold (III) compounds as new family of anticancer drugs. Bioinorg. Chem. Appl. 2003, 1, 177-187.

(25) Zou, T.; Lum, C. T.; Lok, C.-N.; Zhang, J.-J.; Che, C.-M. Chemical biology of anticancer gold(III) and gold(I) complexes. Chem. Soc. Rev. 2015, 44, 8786-8801.

(26) Ronconi, L.; Giovagnini, L.; Marzano, C.; Bettìo, F.; Graziani, R.; Pilloni, G.; Fregona, D. Gold dithiocarbamate derivatives as potential antineoplastic agents: design, spectroscopic properties, and in vitro antitumor activity. Inorg. Chem. 2005, 44, 1867-1881.

(27) Ronconi, L.; Marzano, C.; Zanello, P.; Corsini, M.; Miolo, G.; Maccà, C.; Trevisan, A.; Fregona, D. Gold (III) dithiocarbamate derivatives for the treatment of cancer: solution chemistry, DNA binding, and hemolytic properties. J. Med. Chem. 2006, 49, 1648-1657.

(28) Chen, D.; Milacic, V.; Frezza, M.; Dou, Q. Metal complexes, their cellular targets and potential for cancer therapy. Curr. Pharm. Des. 2009, $15,777-791$.

(29) Cattaruzza, L.; Fregona, D.; Mongiat, M.; Ronconi, L.; Fassina, A.; Colombatti, A.; Aldinucci, D. Antitumor activity of gold(III)dithiocarbamato derivatives on prostate cancer cells and xenografts. Int. J. Cancer 2011, 128, 206-215.

(30) Buckley, R. G.; Elsome, A. M.; Fricker, S. P.; Henderson, G. R.; Theobald, B. R. C.; Parish, R. V.; Howe, B. P.; Kelland, L. R. Antitumor properties of some 2-[(dimethylamino)methyl] phenylgold(III) complexes. J. Med. Chem. 1996, 39, 5208-5214.

(31) Parish, R. V.; Howe, B. P.; Wright, J. P.; Mack, J.; Pritchard, R. G.; Buckley, R. G.; Elsome, A. M.; Fricker, S. P. Chemical and biological studies of dichloro(2-((dimethylamino) methyl) phenyl) gold(III). Inorg. Chem. 1996, 35, 1659-1666.
(32) Pizarro, A. M.; Habtemariam, A.; Sadler, P. J. Activation Mechanisms for Organometallic Anticancer Complexes. In Medicinal Organometallic Chemistry; Springer, 2010; pp 21-56.

(33) Anthony, E. J.; Bolitho, E. M.; Bridgewater, H. E.; Carter, O. W. L.; Donnelly, J. M.; Imberti, C.; Lant, E. C.; Lermyte, F.; Needham, R. J.; Palau, M.; Sadler, P. J.; Shi, H.; Wang, F.-X.; Zhang, W.-Y.; Zhang, Z. Metallodrugs are unique: opportunities and challenges of discovery and development. Chem. Sci. 2020, 11, 12888-12917.

(34) Pradhan, A. K.; Shyam, A.; Mondal, P. A detailed quantum chemical investigation on the hydrolysis mechanism of osmium (iii) anticancer drug, (ImH) $\left[\right.$ trans-OsCl $\left.{ }_{4}(\mathrm{DMSO})(\mathrm{Im})\right](\mathrm{Os}-\mathrm{NAMI}-\mathrm{A}$; Im = imidazole). New J. Chem. 2021, 45, 5682-5694.

(35) Fricker, S. P. A screening strategy for metal antitumor agents as exemplified by gold (III) complexes. Met.-Based Drugs 1999, 6, 291300.

(36) Saggioro, D.; Rigobello, M. P.; Paloschi, L.; Folda, A.; Moggach, S. A.; Parsons, S.; Ronconi, L.; Fregona, D.; Bindoli, A. Gold (III)dithiocarbamato complexes induce cancer cell death triggered by thioredoxin redox system inhibition and activation of ERK pathway. Chem. Biol. 2007, 14, 1128-1139.

(37) Da Silva Maia, P. I.; Deflon, V. M.; Abram, U. Gold(III) complexes in medicinal chemistry. Future Med. Chem. 2014, 6, 15151536.

(38) Messori, L.; Abbate, F.; Marcon, G.; Orioli, P.; Fontani, M.; Mini, E.; Mazzei, T.; Carotti, S.; O’Connell, T.; Zanello, P. Gold (I. I. I.) complexes as potential antitumor agents: solution chemistry and cytotoxic properties of some selected gold (III) compounds. J. Med. Chem. 2000, 43, 3541-3548.

(39) Lempers, E. L. M.; Reedijk, J. Interactions of Platinum Amine Compounds with Sulfur-Containing Biomolecules and DNA Fragments. In Advances in Inorganic Chemistry; Elsevier, 1991; pp 175-217.

(40) Lu, J.; Holmgren, A. Thioredoxin system in cell death progression. Antioxid. Redox Signaling 2012, 17, 1738-1747.

(41) Gabbiani, C.; Mastrobuoni, G.; Sorrentino, F.; Dani, B.; Rigobello, M. P.; Bindoli, A.; Cinellu, M. A.; Pieraccini, G.; Messori, L.; Casini, A. Thioredoxin reductase, an emerging target for anticancer metallodrugs. Enzyme inhibition by cytotoxic gold (III) compounds studied with combined mass spectrometry and biochemical assays. Med. Chem. Commun. 2011, 2, 50-54.

(42) Mohamed, M. M.; Sloane, B. F. Cysteine Cathepsins: Multifunctional enzymes in cancer. Nat. Rev. Cancer 2006, 6, 764-775.

(43) Urig, S.; Fritz-Wolf, K.; Réau, R.; Herold-Mende, C.; Tóth, K.; Davioud-Charvet, E.; Becker, K. Undressing of phosphine gold (I) complexes as irreversible inhibitors of human disulfide reductases. Angew. Chem., Int. Ed. 2006, 45, 1881-1886.

(44) Nguyen, P.; Awwad, R. T.; Smart, D. D. K.; Spitz, D. R.; Gius, D. Thioredoxin reductase as a novel molecular target for cancer therapy. Cancer Lett. 2006, 236, 164-174.

(45) Bertrand, B.; Casini, A. A golden future in medicinal inorganic chemistry: the promise of anticancer gold organometallic compounds. Dalton Trans. 2014, 43, 4209-4219.

(46) Roder, C.; Thomson, M. J. Auranofin: repurposing an old drug for a golden new age. Drugs $R D$ 2015, 15, 13-20.

(47) Liao, J.; Zhao, H.; Zhou, L. Theoretical study on the bifunctional substitution reactions between gold (III) dithiocarbamate derivative $\mathrm{Au}$ $(\mathrm{DMDT}) \mathrm{Cl} 2(\mathrm{DMDT}=\mathrm{N}, \mathrm{N}$-dimethyldithiocarbamate) and target molecules. Comput. Theor. Chem. 2014, 1048, 84-94.

(48) Tolbatov, I.; Coletti, C.; Marrone, A.; Re, N. Insight into the substitution mechanism of antitumor $\mathrm{Au}(\mathrm{I}) \mathrm{N}$-heterocyclic carbene complexes by cysteine and selenocysteine. Inorg. Chem. 2020, 59, $3312-3320$.

(49) Tolbatov, I.; Marzo, T.; Coletti, C.; La Mendola, D.; Storchi, L.; Re, N.; Marrone, A. Reactivity of antitumor coinage metal-based Nheterocyclic carbene complexes with cysteine and selenocysteine protein sites. J. Inorg. Biochem. 2021, 223, 111533-111540.

(50) Lau, J. K.-C.; Ensing, B. Hydrolysis of cisplatin-a first-principles metadynamics study. Phys. Chem. Chem. Phys. 2010, 12, 10348-10355. 
(51) Raber, J.; Zhu, C.; Eriksson, L. A. Activation of anti-cancer drug cisplatin-is the activated complex fully aquated? Mol. Phys. 2004, 102, 2537-2544.

(52) Reddy, B. V. P.; Mukherjee, S.; Mitra, I.; Mahata, S.; Linert, W.; Moi, S. C. Hydrolysis mechanism of anticancer drug lobaplatin in aqueous medium under neutral and acidic conditions: A DFT study. Chem. Phys. Lett. 2016, 663, 115-122.

(53) Pearson, R. G. Absolute electronegativity and hardness correlated with molecular orbital theory. Proc. Natl. Acad. Sci. U.S.A. 1986, 83, 8440-8441.

(54) Pradhan, A. K.; Mondal, P. Quantum chemical investigation on the interaction of cysteine and DNA purine bases with aquated ruthenium (III) anticancer drug $(\mathrm{ImH})\left[\right.$ trans- $\left.\mathrm{RuCl}_{4}(\mathrm{Im})_{2}\right]$. Comput. Theor. Chem. 2020, 1172, 112664-112674.

(55) Frisch, M. J.; Trucks, G. W.; Schlegel, H. B.; Scuseria, G. E.; Robb, M. A.; Cheeseman, J. R.; Scalmani, G.; Barone, V.; Mennucci, B.; Petersson, G. A. et al. Gaussian 09, Revision B.01; Gaussian, Inc.: Wallingford, CT, 2010.

(56) Becke, A. D. Density-functional exchange-energy approximation with correct asymptotic behavior. Phys. Rev. A 1988, 38, 3098-3100.

(57) Perdew, J. P.; Burke, K.; Wang, Y. Generalized gradient approximation for the exchange-correlation hole of a many-electron system. Phys. Rev. B 1996, 54, 16533-16539.

(58) Hariharan, P. C.; Pople, J. A. The effect of d-functions on molecular orbital energies for hydrocarbons. Chem. Phys. Lett. 1972, 16, 217-219.

(59) Becke, A. D. Density-functional thermochemistry. III. The role of exact exchange. J. Chem. Phys. 1993, 98, 5648-5652.

(60) Lee, C.; Yang, W.; Parr, R. G. Development of the Colle-Salvetti correlation-energy formula into a functional of the electron density. Phys. Rev. B 1988, 37, 785-789.

(61) Cossi, M.; Rega, N.; Scalmani, G.; Barone, V. Energies, structures, and electronic properties of molecules in solution with the C-PCM solvation model. J. Comput. Chem. 2003, 24, 669-681.

(62) Gonzalez, C.; Schlegel, H. B. An improved algorithm for reaction path following. J. Chem. Phys. 1989, 90, 2154-2161.

(63) Ehlers, A. W.; Böhme, M.; Dapprich, S.; Gobbi, A.; Höllwarth, A.; Jonas, V.; Köhler, K. F.; Stegmann, R.; Veldkamp, A.; Frenking, G. A set of f-polarization functions for pseudo-potential basis sets of the transition metals Sc-Cu, Y-Ag and La-Au. Chem. Phys. Lett. 1993, 208, $111-114$.

(64) Carpenter, J. E.; Weinhold, F. Analysis of the geometry of the hydroxymethyl radical by the "different hybrids for different spins" natural bond orbital procedure. J. Mol. Struct.: THEOCHEM 1988, 169, $41-62$.

(65) Reed, A. E.; Weinstock, R. B.; Weinhold, F. Natural Population Analysis. J. Chem. Phys. 1985, 83, 735-746.

(66) Connors, K. A. Chemical Kinetics: The Study of Reaction Rates in Solution; Wiley-VCH Verlag GmbH, 1990.

(67) Koopmans, T. Über die Zuordnung von Wellenfunktionen und Eigenwerten zu den einzelnen Elektronen eines Atoms. Physica 1934, 1, 104-113.

(68) Parr, R. G.; Szentpály, L. V.; Liu, S. Electrophilicity index. J. Am. Chem. Soc. 1999, 121, 1922-1924. 